$1-1-1958$

\title{
Parasitism of Calcarisporium parasiticum on species of Physalospora and related fungi
}

\author{
H. L. Barnett
}

Virgil Greene Lilly

Follow this and additional works at: https://researchrepository.wvu.edu/ wv_agricultural_and_forestry_experiment_station_bulletins

\section{Digital Commons Citation}

Barnett, H. L. and Lilly, Virgil Greene, "Parasitism of Calcarisporium parasiticum on species of Physalospora and related fungi" (1958). West Virginia Agricultural and Forestry Experiment Station Bulletins. 420T.

https://researchrepository.wvu.edu/wv_agricultural_and_forestry_experiment_station_bulletins/645 @ WVU. It has been accepted for inclusion in West Virginia Agricultural and Forestry Experiment Station Bulletins by an authorized administrator of The Research Repository @ WVU. For more information, please contact ian.harmon@mail.wvu.edu. 


\section{THE AUTHORS}

H. L. BARnetr is Mycologist at the West Virginia University Agricultural Experiment Station and Professor of Mycology in the College of Agriculture, Forestry, and Home Economics, Virgil Greene Lilly is Physiologist at the West Virginia University Agricultural Experiment Station and Professor of Physiology in the College of Agriculture, Forestry, and Home Economics.

WEST VIRGINIA UNIVERSITY

Agricultural Experiment Station

College of Agriculture, Forestry, and Home Economics

A. H. Vanlandingham, Acting Director

MORGANTOWN 
method by which it obtains nutrients from living host cells? Perhaps a more workable approach to the question of differences among plant pathogens would lie in the study of the parasites that cause little or no obvious danage to the host during this period of their development, as opposed to parasites that kill the host or its parts by means of enzymes or toxins. These two groups of parasites have been designated as balanced parasites and destructive parasites (Bessey, 1935; Lilly and Barnett, 1951).

The balanced parasites of filamentous fungi include some of the most suitable organisms for the study of the basic principles of parasitism. The use of fungus hosts has many advantages: (1) Most of these fungi are rapid growers and complete their life cycle in a few days or weeks and it is possible to conduct a large number of experiments in a minimum time; (2) The hosts can be grown on synthetic media of known composition; (3) Comparatively little space and special equipment are required; (4) Rigid control of the enviromment is possible; (5) Effects of the parasite on the host are frequently reflected by an inhibition of growth which can be measured accurately.

Many host-parasite combinations are available to the interested research mycologist using modern methods and equipment. The discovery and publication of new facts and idleas on parasitism, even though they may seem unimportant when considered alone, is the only way we can hope to reach an understanding of parasitism as a way of life.

One of the earliest mycologists to recognize the parasitic habit of some species on other fungi was Brefeld (1872), who studied the growth of Syncephalis sp., Chateocladium jonesii and Piptocephalis freseniana on other Mucorales. He clescribed and illustrated the haustoria of $P$. fresenimu in the host mycelium. Van Tieghem (1875) demonstrated similar hatustoria produced by other upecies of Piptocephalis. Matruchot $(19000)$ was one of the lirst to determine the host range of a parasite lungus, using P. tieghemianu.

Recent studies of parasitisn in species of Piptocephalis have included those by Doblss and English (1954), Leadbeater and Mercer (1957), Berry and Barnett (1957), and Berry (1957). All species studied produce slender branched haustoria in the host cells and the host range is similar for all species, except $P$. xenophila. Dobbs and English found that this species is capable of parasitizing species of ascomycetes and imperfect fungi as well as several species of Mucorales. No species of Piptocephalis has been grown successfully in the absence of a living host.

Ayres $(1933,1935)$ found that Dispira cormuta is similar to known specics of Piptocephalis in production of haustoria and in host range. 
D. comma, howerer, differed in its ability to grow and sporulate on egre yolk, beef, swordfish and rat dung in the absence of a host fungus.

A second mode of parasitism among fungi was described loy burgeff (1924) for Chaetocladimm and Parasitella simplex. These parasites made contact with and dissolved a hole m the wall of the host hypha, allowing the host nuclei to pass into a specialiced basal cell of the parasite. This was followed by growth of the parasite. The genera Piptocephalis. Syncephalis, Dispira, Chaetocladium and Parnsitella may be classed as balanced parasites, since they do not clestroy the host mycelium and usually cause little or no visible clamage to the host.

A third mole of parasitism is representcel by Papulospora storeri on Rhizoctonia solami, described by Wamen (1918), and by Rhizoctomia solani principally on species of . Aucorales and Peronosporales, described by Butler (1957). In this type the hyphac of the partsite twine aromul the host hyplac but form no haustoria or specializel points of contact. After a short period of growth the parasite kills the host and penetrates the cells. Numerous fungi over-grow and attack other fungi, but the degree of parasitism varies greatly in different species. The details of the mamner in which these parasites kill the hosts are unkmown, but it is assumed that the specific substances causing death of the host cells are of the nature of en/ymes or toxins secreted by the parasite.

Perhaps similar to the destructive parasites are those fungi known to produce diffusable antibiotics and to inhibit the growth of other lungi at a distance. It is doubtul whether this type of artion can lxe considered as truc parasitism, but in some cases it is difficult to draw a sharp line between antibiotic action and parasitism.

So little is known about other parasites that their mode of parasitism cannot be classified. Darluca filum on rusts and Ciccimolubu cesati on powdery mildews are anomg the few hyperparasites growing on hosts that are themselves obligate pallasites of higher plants. The details of these relationships are little knomn. ()ther relationships amaiting

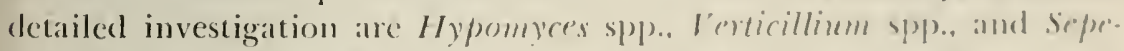

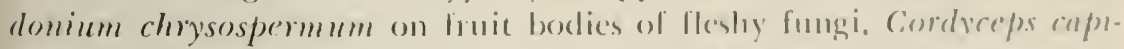

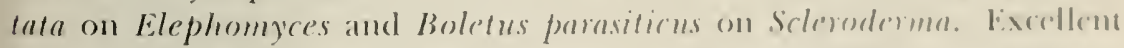

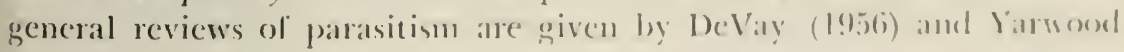
$(1956)$.

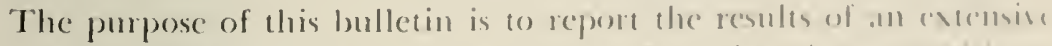

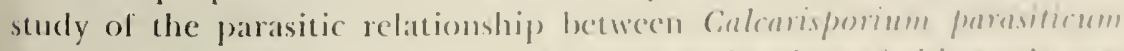
Barnett and its lungus hosts. One of the main amis of this studs was to learn more of the basic principles of the palasitinn and anistane hu the use of a parasite of other fungi. 


\section{DESCRIPTION AND CLASSIFICATION OF PARASITE}

Calcarisporium parasiticum was first discovered in 1954, growing on a culture of Physalospora glandicola (Schw.) Stevens (I)othiorella quercina Cke. and Ellis) isolated from an oak tree suspected of having oak wilt. The white powdery appearance of the parasite made a striking contrast with the clark mycelium of the host (Fig. 1). Since the spores failed to germinate in water or on synthetic media and the fungus failed to develop further after germination on malt extract-yeast extract medium, the parasite was maintained on its host in tubes under refrigeration. Five additional isolates were obtained from cultures of $P$. glandicola in 1956. All isolates originated from different oak trees.

A search through the avililable literature failed to reveal any species to which this fungus could be assigned. However, it was undoubtedly closely related to two genera, Calcarisporium and Hansfordia (See Hughes, 1951). The well-developed conidiophores of the parasite sometimes bear whorls of 3 to 6 sporogenous cells (phialicles) at 2 or more levels. The long verticillate conidiophores are believed to be more characteristic, although shorter conidiophores bearing fewer sporogenous cells are more abundant (Figs. 3, 4). Verticillate conidiophores are formed only under highly favorable conditions and may reflect a nearoptimum nutritional relationship with the host.

It was concluded that this parasite was an undescribed species and for the sake of convenience in referring to the fungus in the present study it was necessary to give it a name. On the basis of genus description (Lindau in Engler and Prantl, 1900), it was believed that the species could be placed correctly in the genus Calcarisporium. Therefore, the parasite was described recently as a new species (Barnett, 1958) under the name of Calcarisporium parasiticum. Only a brief description of its outstanding characters, with illustrations, will be included in this paper.

\section{Calcarisporium parasiticum, THE PARASITE}

Mycelium hyaline, septate, sparsely branched, not extensive, mostly 1.5-3 $\mu$ wide; conidiophores hyaline, variable, simple or branched, short or long, reaching a length of about $0.5 \mathrm{~mm}$, the main axis $3-4.5 \mu$ wide; sporogenous cells (phialides) arising from the conidiophores singly, in pairs, or in whorls of $3-6$ from different levels of the conidiophore, broad(') at the sterile basal portion, narrowed toward the fertile apical portion which continues to elongate, producing conidia in a loose ovoid or cylindrical cluster; conidia produced apically on successive new growing tips, hyaline, dry, narrowly obovate to elliptical, usually narrower at the base, $2.5-4 \times 6-10 \mu$; spore scars on short wart-like or peg-like projections. Parasitic on mycelium of certain other fungi. Known only from 6 isolates found growing on Physalospora glandicola in culture. A mutant 


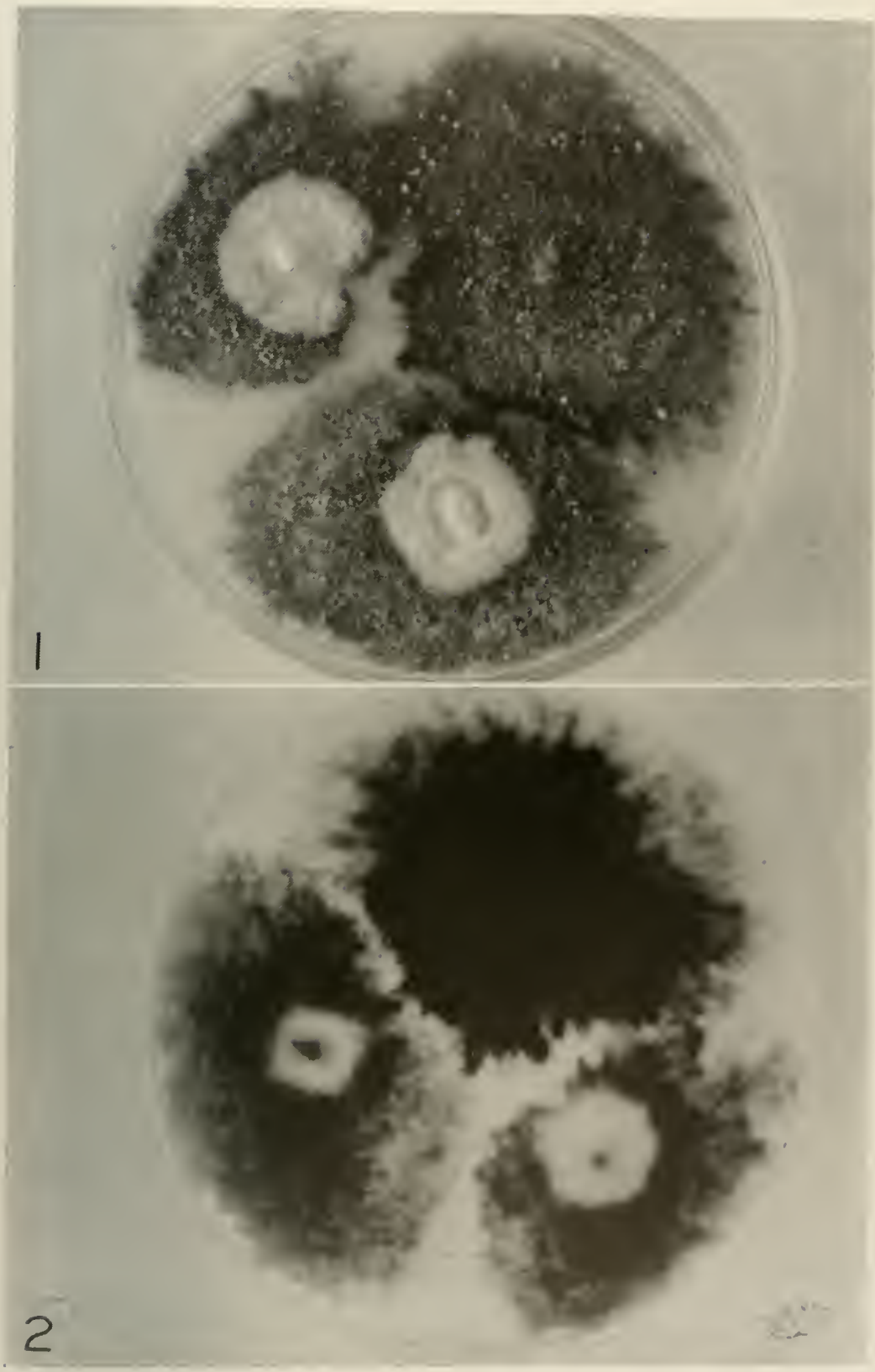

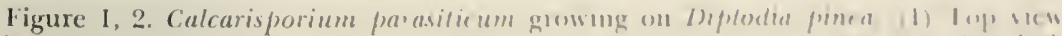

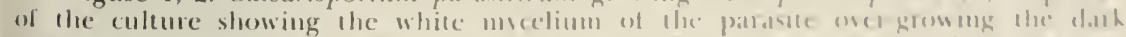

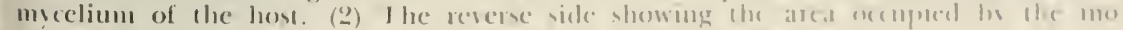

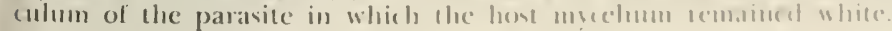



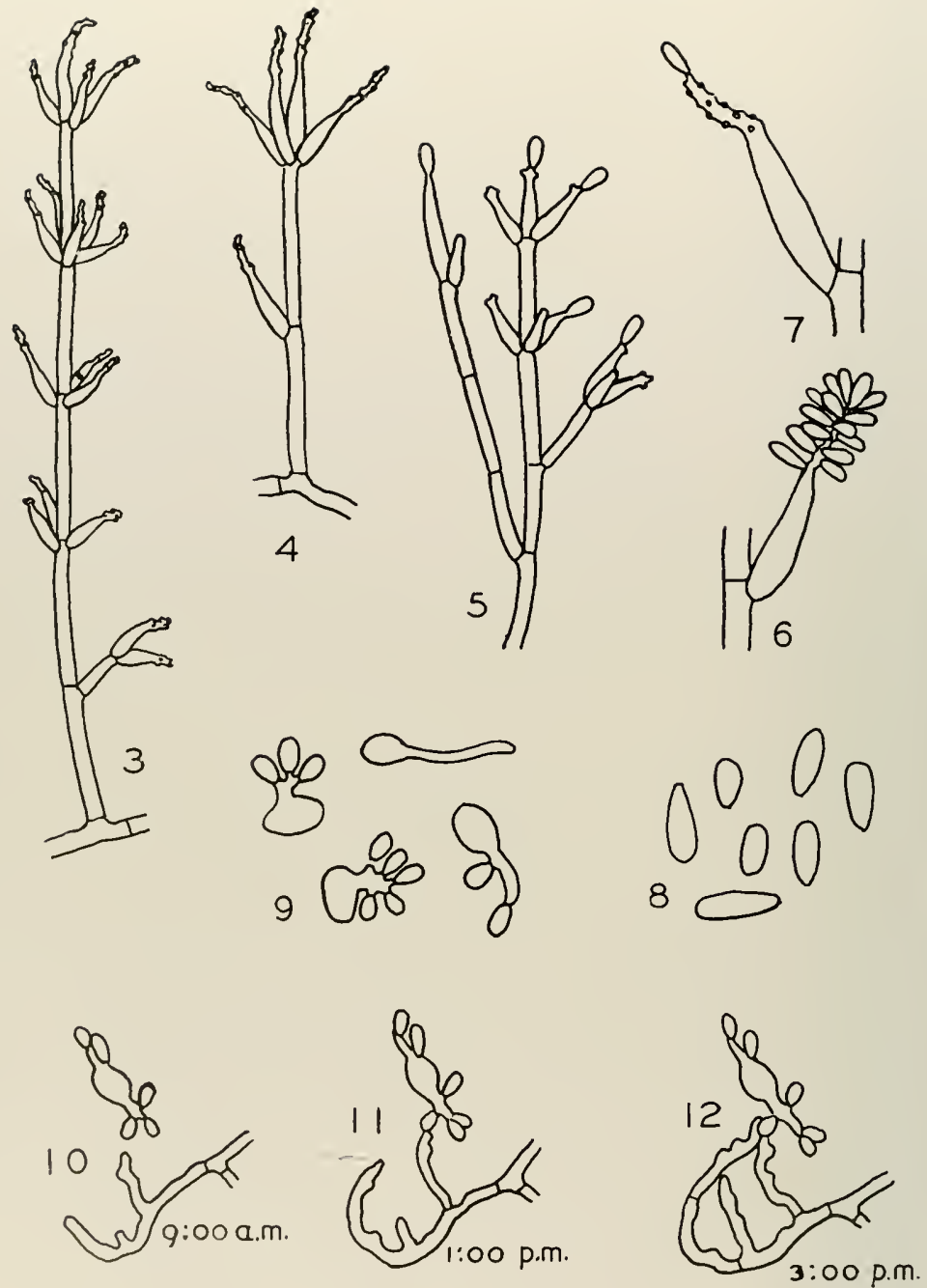

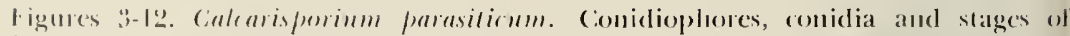
desclepment mutil contact is made between loost and parasite. (3) In mumsually tall, well dereloped condelophore showing the typical verticillate arrangenent of the sporogenous cells. (4) I shorter conicliophore bearing fewer sporogenous cells, more common than the cype shown in 3. (5) An immature conidiophore showing the typical formation of the lateral sporogenous cells after the terminal cell has produced spores. (6) I sporogenous cell bearing a loose cluster of conidia. (7) A sporogenous cell with conidia removed, showing the wart-like spore scars. (8) Conidia. (9) Germinating condia slrowing procluction of secondary spores. (10-12) Time lapse drawings showing in sequence the positive tropic response of the host hyphae toward the germinated spore of the parasite, covering a period of thee hours. 
discovered during the course of this study produced a greater amount of aerial mycelium and fewer spores than the parent culture. Characteristics of the conidiophores, sporogenous cells, and conidia are shown in Figures 3-7.

\section{Materials and Methods}

The experiments performed in this study were so varied that most of the details are given with the description of the individual experinnent. A few general methods that apply to most of the experiments are given here. Glucose-yeast extract agar was used as the standard medium for many experiments. It has the advantage of being easy to prepare, in an excellent medium for the growth of most lungi in Petri dishes, and is clear enough for direct microscopic study of the fungi during growth. The concentrations of the ingredients were modificd als desired. Concentrations given throughout the paper are expressed in grans per liter. For example, a glucose-yeast extract (10-1) agar medium contains $10 \mathrm{~g}$. of glucose, $1 \mathrm{~g}$. of yeast extract, and $20 \mathrm{~g}$. of agar per liter. Media not containing a natural product, such as yeast extract, were supplenented with $\mathrm{KH}_{2} \mathrm{PO}_{4}, 1 \mathrm{~g}$.: $\mathrm{MgSO}_{4}, 0.5 \mathrm{~g}$; and microelement solution, ${ }^{1} 2 \mathrm{ml}$. The $\mathrm{pH}$ was adjusted to 6.0 before autoclaving at 15 pounds stean pressure for 15 minutes. Each Petri dish contained approximatcly 20 m of medium. Liquid media were dispensed accurately, $25 \mathrm{ml}$ per $250-\mathrm{ml}$ Erlemneyer flask. Unless otherwise stated, cultures were incubated in at constant temperature room at $25^{\circ} \mathrm{C}$. and received 12 hours of artificial light each clay.

Inoculations were usually made by bits of mycelium of lume cultures on agar and a drop of spore suspension of the partaste. An ample supply of parasite spores for inoculum free from host cell wan diflicule to obtain in the early experiments. However, an abundance of spenes was obtained after it was discovered how the patasite could be induced to sporulate on agar medium, in the absence of a here. This methexl is discussed in a later section of this bulletin. Hone mecelium from

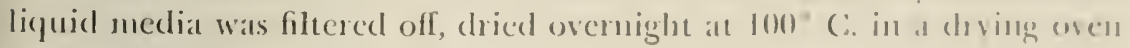
and reighed.

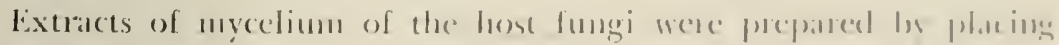

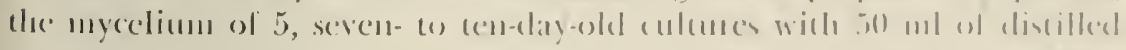

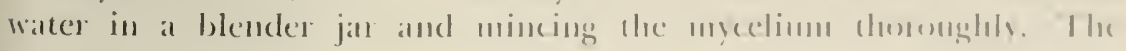

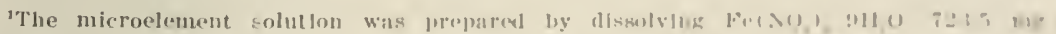

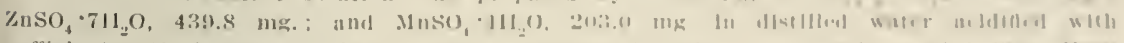

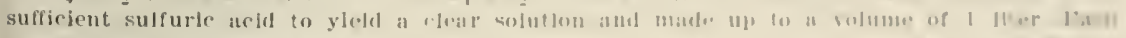

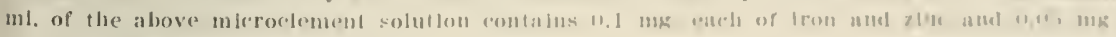
of manganese. 
mycetial tragnents were then removed by filtering through several thicknesses of filter paper and the filtrate was then sterlized by autoclaving or passing through a sintered gliss filter.

Most of the test hosts were obtained from the West Virginia University Fungi Culture Collection. A few were obtained from the Centrabureau voor Schimmelcultures at Barn, and two from the American Type Culture Collection. Some were kindly furnished by Dr. C. T. Rogerson, of Kansas State College.

\section{Experimental Results}

\section{HOST RANGE}

During the course of this sudy approximately 40 species of intperfect fungi and asconycetes were tested as possible hosts of C. parasiticum. This was done by placing bits of mycelium or spores of the test fungus on an agar plate and adding spores of the parasite. Mostly a malt extract-yeast extract (10-1) agar medium was used.

The appearance of typical conicliophores of the parasite on the host mycelium was used as the criterion of parasitism. Usually these could be seen and recognized in mass with the malded cye, but cultures were always examined with the stereoscope or compound microscope. Conidiophores of the parasite were usually apparent alter 2 or 3 days, but a period of 2 weeks was allowed for possible delayed development on some of the test fungi.

Table I. Origin of Isolates of the Host Fungi ani) Relative SUSCEPTIBILITY

\begin{tabular}{|c|c|c|c|c|}
\hline Host Fungus & $\begin{array}{c}\text { No, OF } \\
\text { 1 SOLATES }\end{array}$ & Sovrce & STATE & SUSCEPTIBILITY \\
\hline Physalostora oblusu & 23 & apple & W.Va. & high \\
\hline P. whtusat .. & 3 & oak & W.Va. & high \\
\hline$P$. ollusa ......... & 2 & red busl & W.Va. & high \\
\hline P. alituste & 1 & honey Iorust & W.Va. & hight \\
\hline$P$. whtusat & 1 & 'quince & W.Vid. & hight \\
\hline P. alendierdete & 26 & oak & W.Va. & high \\
\hline$P$. slandicolne & 2 & oak & Kansas & higlt \\
\hline P. ilicis & 1 & liolly & I'sknown & low \\
\hline Ginimuerdin biflerllii & 1 & grape & WV.Va. & higlı \\
\hline Botryospherin ribis & 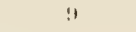 & apple & W.Va. & highl \\
\hline B. ribis & 2 & sweet gum & W.Via. & high \\
\hline B. ribis & 1 & red bud & II Va. & high \\
\hline B. rilis & 1 & oak & W.Va. & high \\
\hline B. ribis & 1 & elm & Kallsas & high \\
\hline B. ribis & 1 & Lonicert & Kansas & high \\
\hline Diplodiut pinete ........ & 1 & scotch pine & Lansas & high \\
\hline D. pinen ....... & 1 & Scotch pine & W.Va. & high \\
\hline Coniothyrium sp. .... & 1 & oak & W.Va. & very low \\
\hline Dothiorelli, sp. ...... & 1 & Syringa & Kansas & high \\
\hline
\end{tabular}




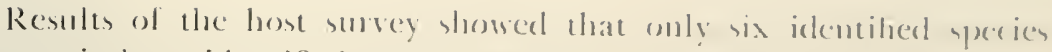
and two isolates identified only to genus were hosts of C. parnsitiomm. 'These were as follows: Physnlosporn oblusa (Schw.) (ike. (spopropsis malormm Peck.), Physalospora glandicola (Schw.) Stevens (I)olhiorella quercina Cke. and Ellis), Physalospon iliris (Schl. ex Fries) Sace. (P/h/-

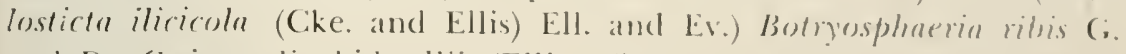

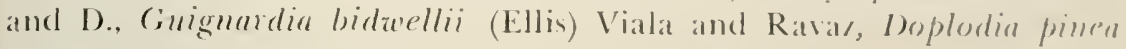
(Desm.) Kickx, Comiollyrimm sp. and Dollimelln s]).

Numerous other species of fungi were tested but none supperted growth of C. parasiticum. Spores of the parasite germinated in the presence of several of the species and contact was even established with wome but there was no further development of the parasite. A list of ale menhost species is given below.

Alternaria tenuis

Ascocliyta imperfecti

Ascochy'ta sorghi

Bispora punctuta

Ceratocystis fagacearmm

Ceratocystis fimbriata

Chaetominm globosum

Chalaropsis sp.

Cladosporimm sp.

Colletolrichum phomosides

Comiothyrinm spp.

Coryueum kunzei

Currularia Imnata

Cytospora sp.

Dendryphiopsis atra

Diplodin zene

Diplodia spp.

Dothiorella (Cephalosporimm) ulmi Endothia parasitica

Fusarium culmormm

Fusicoccum sp.
Gliorladimm rosenm

Glomerella cingulala

Graphimm rigidnm

Hypoxylen punctulatum

Hypoxylon tinctor

Melancominim fuliginemm

Pestalestin spe.

Perriella spe.

Phesalosporea fusca

Plejusalospora mivabeann

Phesalospona mutiln

Phesendospom rhorlina (:i isolates)

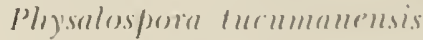

Phesalosponara zoricola

l'ss'udesplen trifolii

reventermetesp.

Rhizontomin solnui

Srlowstimm rolfsii

Sordaria fimirola

stemplevlimm sp.

Ierticillinm allustrtrum

The immonity of Physalospora rhorima (lietk. and Cime) Che.

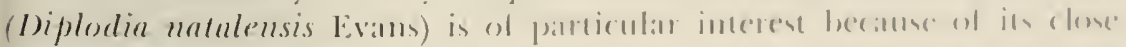

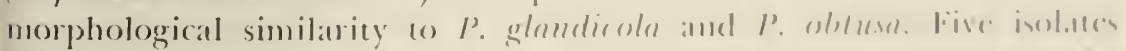

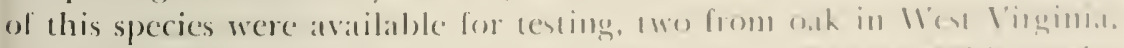

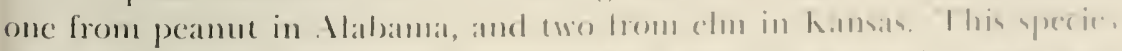

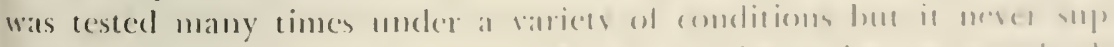

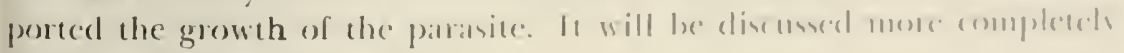
in the section on resistance. 


\section{SPORE GERMINATION}

As a result of experiments on nutritional needs for germination, it was evident that an external factor, other than water and oxygen, is required for germination. Spores of $C$. parasiticum failed to germinate or even to swell in water or on watter agar. On a ghocose-yeast extract agar medium the spores swelled and more than 50 per cent produced germ tubes within 24 hours. The percentage increased during the next 2.1 hours.

The ustal method of gemination was by the production of a short germ tube bearing a few seconclary spores slightly smaller than the primary spore (Fig. 9). The production of spores continued for several days on a favorable medium, even without a host. A small percentage of the spores gave rise to longer germ tubes with delayed formation of secondary spores. No further development occurred on unsupplemented media until after contact with a susceptible host was made Minor differences were found in the germination of spores of two dif lerent isolates (No. 1012 and 1198). Isolate 1198 was characterized by a somewhat lower percentage of germination and a greater number of long germ tubes with delayed sporulation. This isolate was used in the experiments reported in this bulletin, unless specifically stated otherwise.

As high as 50 per cent germination was reached in the presence of certain natural products in the medium. Some of these products were yeast extract, malt extract, wheat germ, green rose leaf, apple pulp, and mycelial cxtracts of Physalospora obtusa, $P$. glandicola and $P$. rhodina. Germination as high as $25-40$ per cent was obtained on agar media containing Casamino Acids, enzymatic hydrolyzed casein and Bactopeptone. Few or no spores germinated on water agar to which cach of the following substances was added singly: potassium acetate, glucose, gultamic acid, thiamine, biotin, coprogen, guanine hydrochloride, amino uracil, soybean protein, rolled oats, oak bark and several amino acids. Spores germinated well (80 per cent or above) in the presence of living mycelium of a host and some non-host fungi. Under this condition there was a greater tendency to produce long germ tubes with delayed sportalation.

On the basis of these results it is concluded that one or more essential spore-germination factors are present in many natural materials and are produced by growing mycelium of the hosts and of some nonhost fungi. It is evident that a more thorough study of germination factors is needed and a continuation of these investigations is planned.

Germination occurs most rapidly on a suitable medium within a temperature range of $25^{\circ}-35^{\circ} \mathrm{C}$. Within this range germination was 40 per cent or greater within 24 hours. No germination occurred at $40^{\circ} \mathrm{C}$. 
The principal effect of lower temperatures was to delay germination. When spores of both $C$. parasiticum and $P$. oblusa were placed together on plates of malt extract-yeast extract agar, germination and parasitim were evident within seven days at temperatures as low as $10^{\circ} \mathrm{C}$. About 10 per cent of the spores that had been frosen continuously in distilled water for 12 months germmated on a favorable medium at $25-$ (.

\section{TROPISM OF HOST HYPHAE TOWARD GERMINATED SPORES OF PARASITE}

During the study of spore germination of c. parasiticum in the presence of the host it was observed many times that contacts between parasite and host are not always due to chance. Host hyphate growing anong scattered spores of the parasite were stimulated to send out short lateral branches toward germinating spores, or less often the (ip) of the main hypha would curve from its normal course and grow directly toward the parasite. The stimulus is assumed to be a chemical substance secreted by the germinating spores. The strength of the reaction. based on distance between host and parasite, appear to vary with the stage of germination, the medium and the speries of host. In one case, cbserved at intervals through the microscope, the host hyphat fo microm away began to turn toward geminated spores of the parasite and required 4 hours to cover the intervening distance and make contart (Figs. 10, 12). There is also evidence that when the host comes within a lew microns of a parasite spore the latter maly put ou a short tube that grows toward the host.

A dilute glucose-yeast extract (3-1) agall medium was siltisfactory for observing tropism of host hyphac. At this dilution and on waten agar the mycelium was sparse enough so that it could be suclied easits with the microscope. The hyphae of $P$. oblusa reacted somewhat more strongly that did P. glandicola. It is of particulat interest thit P'.

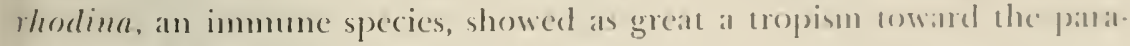
site as did the highly susceptible hosts.

The chemical stimulator is active in high dilution and it is lighls potent. The host hyphate attracted to the paralsite ane frepuemels wielen

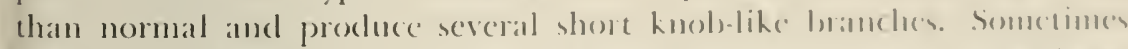

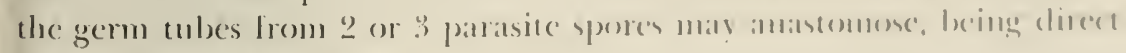
ly attracted to each other.

\section{NIODE OF PARASITISM}

The actual contact between the partisite and hos is 11smalls accom plished by means ol short lateral branches onds a lew microm leng which

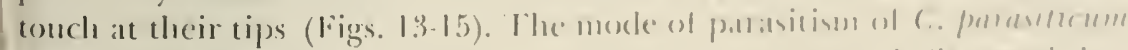

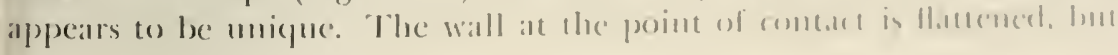



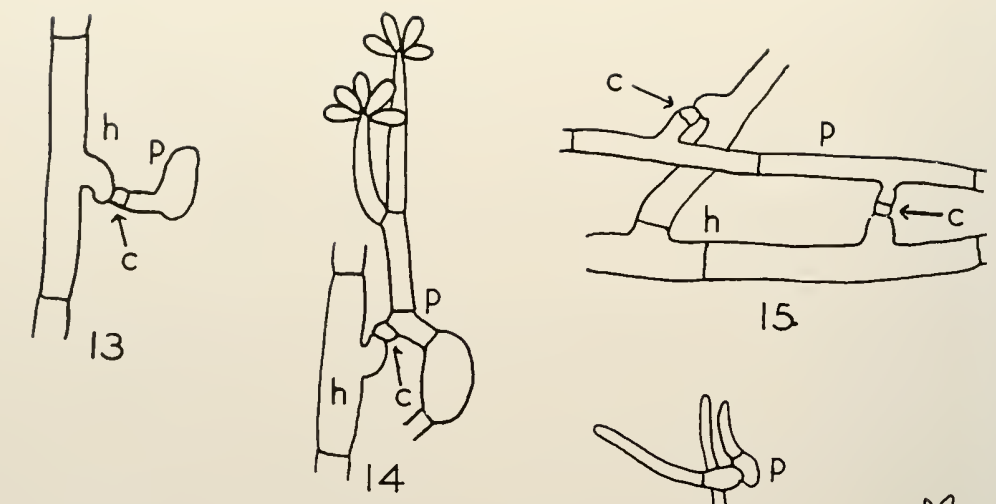

15

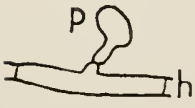

16
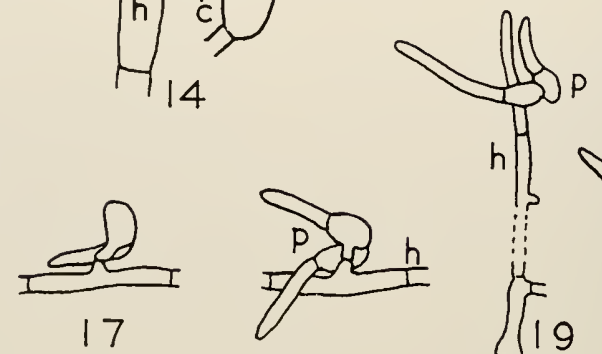

18
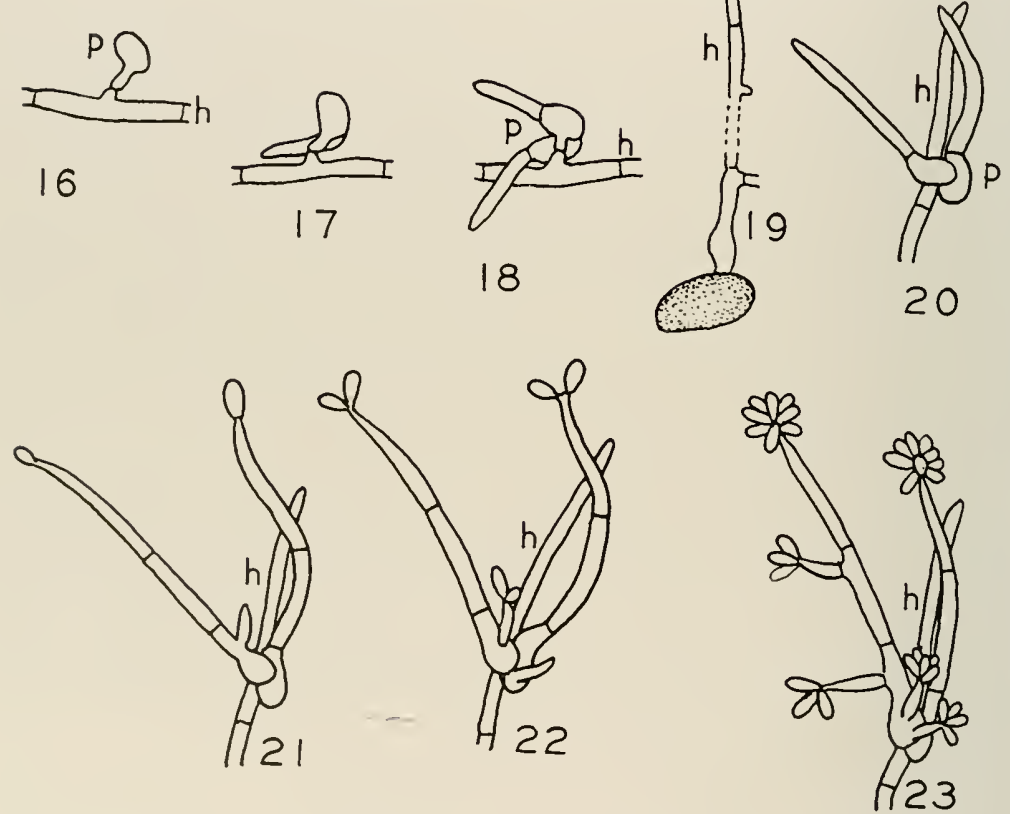

Figures 13-23. Calcarisporium parasiticum. The buffer cell produced at the point (o) hosi-parasite contact and stages in the development of the parasite from the time of host contact until spormlation. (13) The buller cell (c) at the point of contact between germ tube of the parasite (p) and short lateral branch of the host (h). (14) Similar to 13 but after further tevelopment. (15) Buffer cells (c) between host (h) and parasite (p) at the frequent contacts of the mycelia, (16-18) Time-lapse drawings of the same parasite (p) from the time of contact till the production of two hyphae, covering a period of six hours. (19-23) Time-lapse drawings of a parasite (p) from the stage shown in 18 till the production of several clusters of conidia. covering a period of 22 hours. The parasite $(P)$ is attacking a germ tube of $P$. obtusa (h) growing on water agar. Note that no growth of the host hypha $(h)$ occurs lluing this period. 
there is no penctration of the host either by haustoriat or i) nom-specialied branches. Yet, a satisfactory mutritional relationship is establislucel immediately following contact and the parasite begins to develop rapidly within a few hours. This suggests that certain essential mutrients present in the host mycelium pass freely from host te parasite. This movenncut may be initiated or stimulated as a result of increased permeability of the host membrane as a response to the parasite. There is no covidence of any hamful effect on the host, except a reduction in the ratc of growth. C. parasiticum is, therelore, a good example of the balinced type of parasitism.

The actual area of contact between parasite and host is small, usually no more than 2 microns in dianeter. In most cisces there alppears to be a small cell about 2 microms wide fomed at the tip of the parasite hypha where is contalcts the host (Figs. 13, 15). This timy "buffer" cell is not always visible at contact points, possibly due to the position of the hpyhae, but it is believed to occur in all or nearly all cases.

The function of this contact cell is purely a matter of ypeculation at present, but it appears to facilitate a successul patratic relatiomblip. It possibly functions to increase the permeability of the host cell membrane and to absorb the cssential nutricuts from the host. It applatrs to differ from the buffer cell produced between Chatocladinm and Parasitella and their hosts (Burgelf, 192-1). There is no (vidence of an! dissolution of the cell wall by $C$. parsilicmm. The spereat ol the pallatsite over the host colony is accompanticel by freputent (ontated with the mature cells of the host (lig. 15). These contact points and be recognized by the presence of the small buffer cell described abouc. No buffer cells have been observed at contact points between $\quad \therefore$ parmitionm and P. rlodina.

If one assmmes that contate between host and pallasite hyphate ofoms

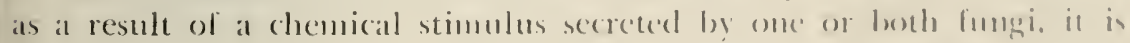
reasomable to conchude that this substance might le llubled amall (1) all

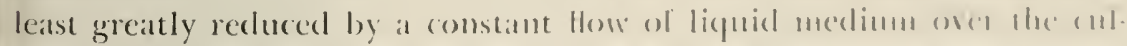

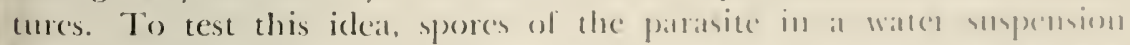

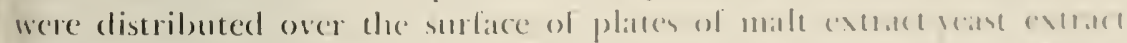

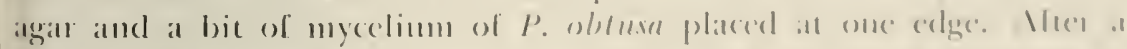

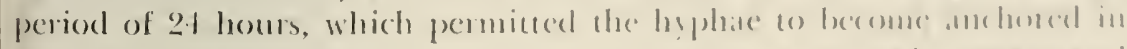

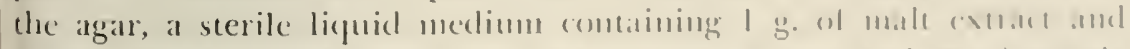

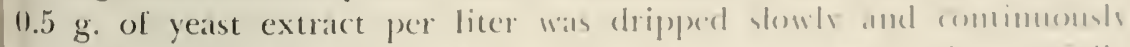

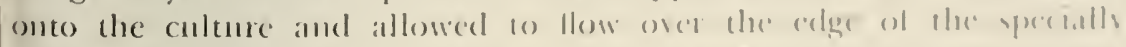

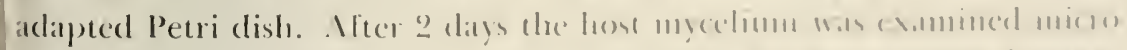

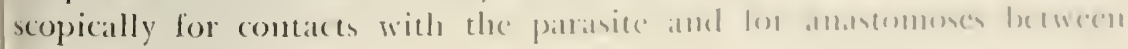


host hyphac. These were compared with the frequency of contacts on agar medium with no treatment. The continuous flow of hiquid medium greatly reduced but dicl not completely eliminate the number of paracitic contacts. Likewise it reduced the number of anastomoses between host hyphae.

\section{GROWTH AND DEVELOPMENT OF THE PARASITE}

One of the striking characteristics of $C$. parasiticum is the rapidity of its development on a highly susceptible host. For the study of the early development of the parasite either water agar or a highly diluted malt-yeast medium was selected because a sparse growth of the mycelimm is esscntial to clear microscopic examination of carly development. A mixture of spores of the parasite and host was used as inoculum. A number of areas on the plates were marked and examined at intervals to follow the rate of development. Stages in development were recorded in a series of drawings (Figs. 16-23). Figures 16-18 show the same individual from the time of contact to the production of two separate branches 6 hours later. Figures 19-23 show a sequence of development of another individual on a hypha from a germinating spore of $P$. obtusa. Under these conditions the parasite produced its first spores about 12 hours alter contact with the host and within 24 hours it had produced several clusters of conidia.

Figures 19-23 illustrate clearly one of the principal effects of $C$. parasiticum on its host. The point of contact in this case (hidden by the parasite in the drawings) was near the tip of the host hypha growing on water agar. During the 23-hour period covered in this sequence the parasitized hypha made no further growth. Yet, it provided the young parasite with sufficient nutrients within this period to develop rapidly and produce six sporogenous cells, each bearing a cluster of conidia. It was apparent that the parasite absorbed through its one point of contact with the host sufficient mutrients for rapid development and in doing so deprived the host of nutrients needed for its own growth. This suggests the possibility that the key matcrial needed by the parasite is also essential to the host.

Stages in the development of the conidiophore of C. parasiticum are shown in Figures 5, 21-23. The conidiophore first appears ats a sender, simple hypha, the apical cell of which may soon produce spores. ln the meantime the condiophore sometines becomes branched. Other sporogenous cells arise as side branches from the main axis of the conidiophore. If the conidiophore hypha is short, only one to a lew sporogenous cells will be produced, but if it is made up of several cells, a large number of sporogenous cells may be produced. It is not clear what factors determine the size of the conidiophore and number of sporogenous cells, 
but it seems certain that nutrition is an important factor. Early lonmat tion of conidiophores is frequent but does not always occur. Alter 2 or :3 days the mycelium of the parasite can be seen growing slowly outward among the hyphae of the host making contact where they cross.

The effects of temperature on growth and development of C. purasiticum were determined using P. obtusa as the host. Plates of malt extract-yeast extract agar were inoculated at three points with mycelium of the host and a clrop of parasite spore suspension added. The cultures were incubated at $5^{\circ}$ intervals in temperature from $5^{\circ}$ to $40^{\circ}$ C. Both the host and the parasite developed within the range of $100^{\circ}$ to $35^{\circ} \mathrm{C}$. with the optimum about $25^{\circ}$ to $90^{\circ}$ C., near the optinum of the host. There was poorer development of the conidiophores at $35^{\circ}$ than at $30^{\circ}$ C., but the number of spores was nearly as great. The principal eflect of temperatures below optimum was to rechec the rate of groweth of both host and parasite, but a few spores were produced at $10^{\circ} \mathrm{C}$.

Experiments to detemine the effects of the carbon soure in the host medium on the growth of the parasite were conducted on sugarglutamic acid (3-1) agar media. Both P. obtuss and $P$. glandicoln were used as hosts. The development of the parasite was essentially the same on both hosts and was not proportional to the growth of the hest. Development and sporulation of $C$. parasiticum werc best on glucose, fructose, galactose, maltose and sorbose, and poorer on lactose and on medium without sugar. Host growth was very slow on sorbose, lut with $P$. obtusa in particular, the parasite completely covered the host mecelium.

The effects of the nitrogen source in the host mediun on the de. velopment of the parasite were tested using the glucose-nitugen mume (10-2) agar media. The initial pH of cach medimm was (b.). The rate of development of the parasite varied with the medium and the hom. Olsservations made on the tenth day were recorded ats trate, poor or sparse, good but with little spread, and excellent and preading (repere-

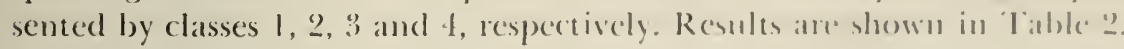

\section{EFFECT OF PARASITE ON GROWTH OF HOST}

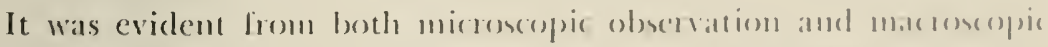

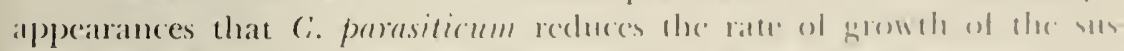

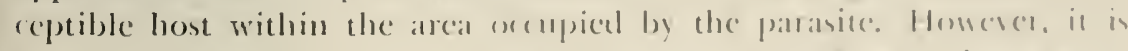

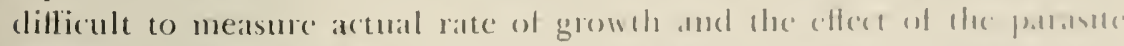
on agar media. Preliminary experiments stowed that the frataite mot

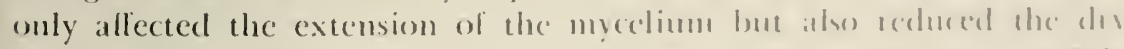
weight of mycelimm produced by the hest. Sime it was mot pemblate

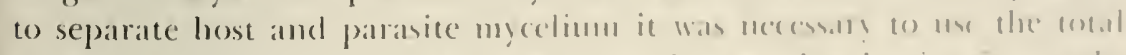
growth of both, with the realiattion that the actual rechetion ind werght 
IABLE 2. GROWTH OF 2 ISOLATES OF (:. parasiticam aN 3 HOSTS GROWN ON DIferent Nitrogen SOUrces. DATA Are from 10-DAY-OLd Culturles

\begin{tabular}{|c|c|c|c|c|c|c|}
\hline \multirow{3}{*}{ NITRoGin Source } & \multicolumn{3}{|c|}{ Parasite Isolate $1012 \mathrm{oN}$} & \multicolumn{3}{|c|}{ PARASITE I SOLATE 1195 ON } \\
\hline & \multicolumn{2}{|c|}{ P. GLANDICOLA } & \multirow{2}{*}{$\frac{\text { P. OBTUSA }}{\text { No. } 1084}$} & \multicolumn{2}{|c|}{ P. GLANDICOLA } & \multirow{2}{*}{$\frac{\text { P. OBTUSA }}{\text { No. } 1084}$} \\
\hline & No. 1138 & No. 1199 & & No. 1138 & No. 1199 & \\
\hline $\mathrm{K} \mathrm{NO}_{3}$ & $3^{*}$ & 3 & 3 & 4 & 4 & 4 \\
\hline Ammonium sulfate .... & 1 & 1 & 2 & 2 & 2 & 2 \\
\hline Ammonium sulfate & & & & & & \\
\hline and $\mathrm{CaCO}_{3} \quad \ldots \ldots \ldots \ldots$ & 1 & 2 & 2 & 2 & 2 & 2 \\
\hline Ammonium tartrate & 2 & 3 & 3 & 3 & 4 & 4 \\
\hline Asparagine & 3 & 3 & 3 & 3 & 4 & 4 \\
\hline Glutamic acid ......... & 3 & 3 & 2 & 3 & $t$ & 4 \\
\hline Phenylalanine ... & 2 & 2 & 3 & 3 & 3 & 4 \\
\hline Casamino Acids ........... & 2 & 3 & 3 & 3 & 4 & 4 \\
\hline
\end{tabular}

* $1=$ trace $: 2=$ poor, sparse $: 3=\operatorname{good}$ but little spread $4=$ excellent and spreading over lıost.

of the host was greater than shown by the differences between the dry weights of the host alone and the host-parasite combination.

An additional effect of the parasite on the highly susceptible host was evident when an agar medium was inoculated with a bit of host mycelium and a drop or two of spore suspension of the parasite. The latter spread out and covered an area about $10 \mathrm{~mm}$. in dianeter. As the host grew outward through this area the mycelium was quickly parasitized and failed to develop the dark melanin pigment characteristic of Physalospora (Fig. 2). The portion of the host mycelimm that extended beyond the parasite soon became dark. The parasite later overgrew the host but did not destroy the pigment in the dark mycelium.

The nitrogen sources in agar media on which the hosts were grown affected the development of the parasite (Table 2). In general the development of the parasite was poor when ammonium sulfate, with or without calcium carbonate, was used and good to excellent on other nitrogen sources. The parasite isolate No. 1198 was somewhat more virulent than isolate No. 1012.

It was also desirable to-detemine if growth in liquid would be similarly affected. $P$. glandicola (Isolate No. 1138) was chosen as the host and isolate 1198 of the parasite was used. The media contained I0 g. glucose and $2 \mathrm{~g}$. of nitrogen source per liter. The initial pH of all nedia was 6.0. The dry weights with $\mathrm{pH}$ reading at all harvests alle slown in Table $\%$.

In all nuediat, except anmonimm sullate withont $\mathrm{Ca} \mathrm{CO}_{3,}$, the total dry weight of host and parasite was less than that of the host alone under the same conditions. It is possible that the nitrogen sources may affect the growth of the parasite directly, but on the basis of observation the direct effect on growth of the parasite alone within the 10-day period of this experiment would be a minor contributing factor. (See a later 


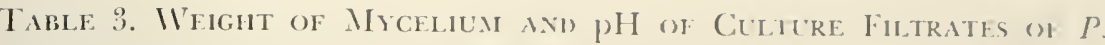

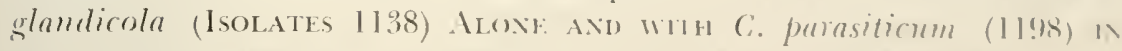

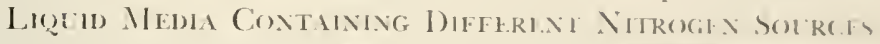

\begin{tabular}{|c|c|c|c|c|c|c|c|c|c|c|c|c|}
\hline \multirow{2}{*}{ 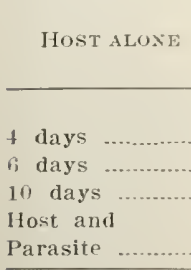 } & \multicolumn{2}{|c|}{$\mathrm{KNO}_{3}$} & \multicolumn{2}{|c|}{$\begin{array}{l}\text { A MMONIL M } \\
\text { STLFATE }\end{array}$} & \multicolumn{2}{|c|}{$\begin{array}{l}\text { A MMONIT: } \\
\text { SiLFATR } \\
\text { \& CaCO:3 }\end{array}$} & \multicolumn{2}{|c|}{$\begin{array}{l}\text { AMMONITM } \\
\text { TAITRATE }\end{array}$} & \multicolumn{2}{|c|}{$\begin{array}{c}\text { Pufixida- } \\
\text { Maxixk }\end{array}$} & \multicolumn{2}{|c|}{$\begin{array}{c}\text { ('ASAMINU) } \\
\text { ACIISE }\end{array}$} \\
\hline & $\begin{array}{l}\mathrm{mg} . \\
47 \\
51 \\
100\end{array}$ & $\begin{array}{l}\mathrm{pH} \\
6.2 \\
7.1 \\
7.7\end{array}$ & $\begin{array}{l}\text { mg. } \\
29 \\
28 \\
3 i\end{array}$ & $\begin{array}{l}\mathrm{pH} \\
2.3 \\
2.6 \\
2.4\end{array}$ & $\begin{array}{l}\mathrm{mg} . \\
105 \\
132 \\
112\end{array}$ & $\begin{array}{l}011 \\
3.5 \\
3.0 \\
3.2\end{array}$ & $\begin{array}{l}\text { mg. } \\
\text { (i) } \\
114 \\
\text { is }\end{array}$ & $\begin{array}{l}\text { pll } \\
3.6 \\
3.3 \\
2.1 \%\end{array}$ & $\begin{array}{l}\text { mg. } \\
17 \\
48 \\
1: 7\end{array}$ & $\begin{array}{l}\text { PII } \\
3.5 \\
3.2 \\
36\end{array}$ & $\begin{array}{l}\text { mg. } \\
114 \\
127 \\
105\end{array}$ & $\begin{array}{l}p 11 \\
4.3 \\
4.2 \\
5.1\end{array}$ \\
\hline 4 days ................ & 18 & 5.7 & 52 & 3.0 & 54 & 5.4 & 27 & 4.1 & $!$ & 4.1 & lin & 1.3 \\
\hline fi days ................. & 38 & 5.9 & 42 & 2.5 & $7 !$ & 2.5 & I! & $3 . \bar{T}$ & $2 \pi$ & 3.7 & 101 & $\therefore .7$ \\
\hline 10 days ................ & $\operatorname{lin}$ & 6.9 & 411 & 2.7 & 97 & 5.5 & 87 & 4.1 & $5: 3$ & 3.7 & l1m & 5. 7 \\
\hline
\end{tabular}

section for method of growing C. purasiticum in absence of living host.)

The effect of the parasite on the host in liquid media is to reduce the rate of growth rather than to deck growth entirely after a lew dis (Table 3). Inhibition is somewhat greater in a potassimm nitratc medium, which allows slower growth of the host than does the hretrolyzed casein medium. Therefore, mapid growth ol the host is mot essential to vigorous parasitism. The greater weight of the honteanisite mixture in the ammonimm sullate medium without calcium carbonate may have been due to the slightly higher pH for the host-parasite culume medium. It is believed that the minimum pH for the host is around 2.4. However, within a more lavoralsle range such a slight difference in pH had no visible effect. Both the host and the parate developed well within the $\mathrm{pH}$ range of 3.2 to 7.0 . In general the prenence of the parasite had little effect on the pH chamges in the media.

It this time it became desimble to determine whether the isolates of C. parasiticum were similar in vimlence and eflect on the host. Foun

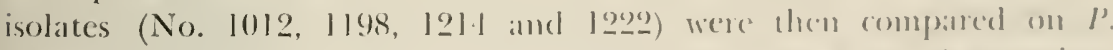
oblusa (isolate No. I08.1) on two media, one with "g.

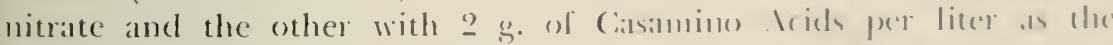

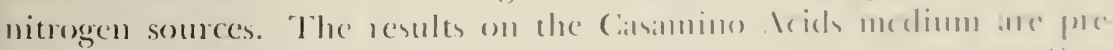

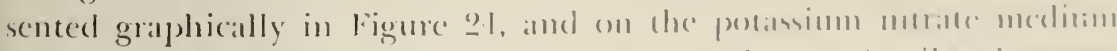

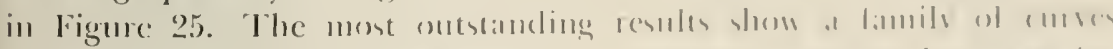

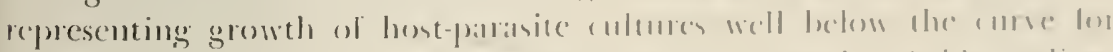

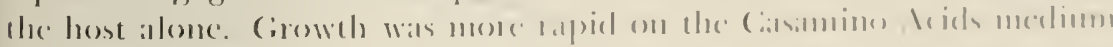

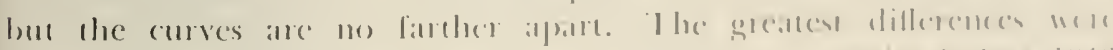

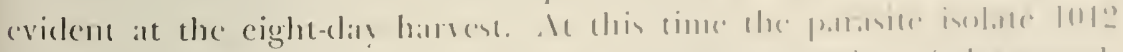

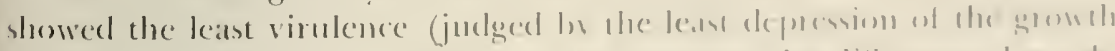

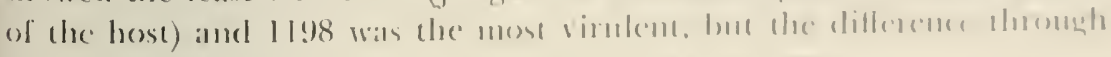

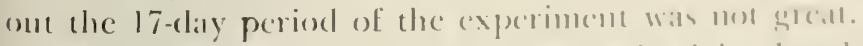

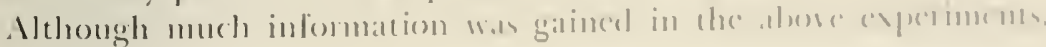




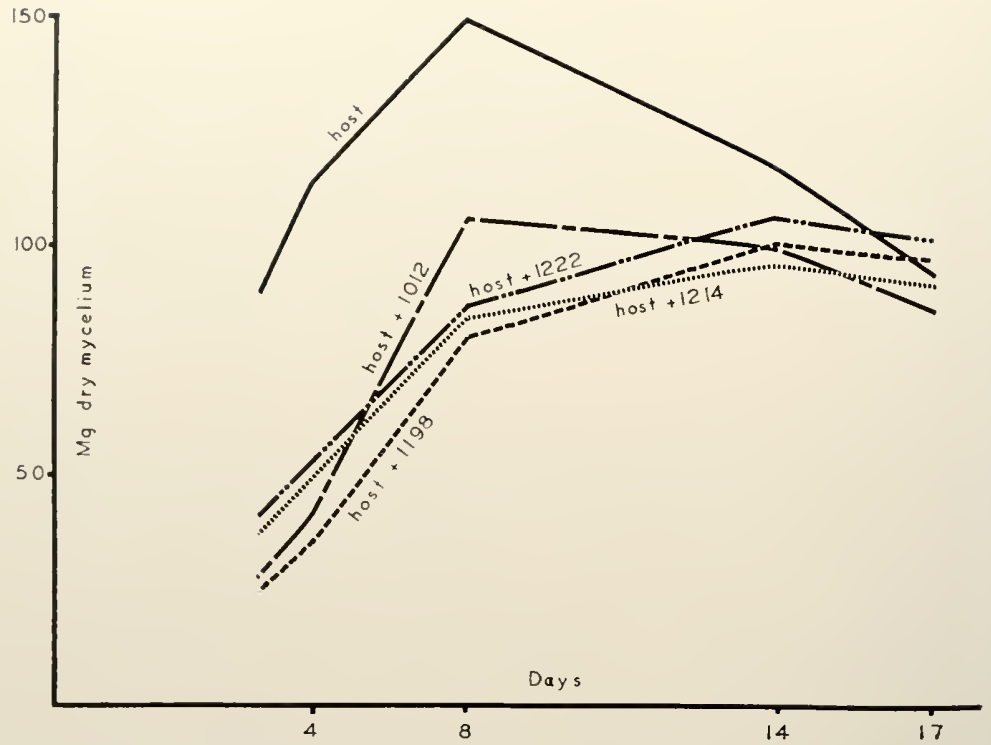

Figure 24. Growth of $P$. obtusa (isolate 1084) alone and in combination with each of four isolates of $C$. parasiticum in a ghucose-Casamino Acids medium.

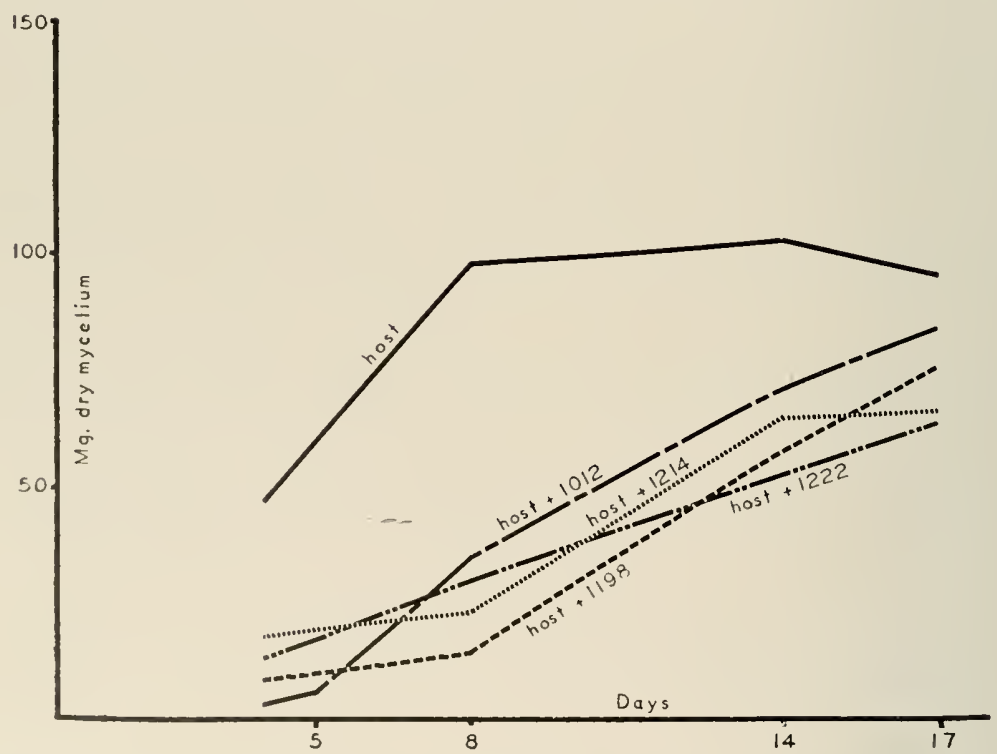

Figure 25. Cirowth of $P$. olntusa (isolate 1084) alone and in combination with each of four isolates of C. parasiticum in glucose-potassium nitrate medium. 
it was still necessary to learn more about the important fátor of time and to follow the cultures more closely during the growth period. More extensive experiments were conducted, lollowing the growth of $P$. glandicoln (No. 11.88) on Casamino lcids and potassimm nitrate mucliat, with and without the parasite (No. 1198). The results are shomen by growth curves in Figure 26, and $\mathrm{pH}$ changes of the mediun during growth are shown in Figure 27.

The inhibitory effects of the parasite are striking hy the fourth daly on both media. At any given time through the 20th day the weight of the host-parasite culture was less than that of the host. This man true on both media. From observation, growth of the parasite was approximately equal on both media, but the proportion of paranite to hout was greater on the nitrate medimm. It was not possible to descrminc. whether the parasite reached a maximum weight, but it appeared that the parasite continued to grow and spormbate well beyond the point at which the host reached maximum weight.

Duplicate experiments were carried out simulaumously using $P$ '. obtusa (No. 1084) as the host. The growth curves atre presented in Figure 28 and the pH changes in Figure 29. In gencral the resulis are similar to those when P. glamdicola wats the host, but even greater ef. lects of the parasite are evident. The decline in reight of $P$. olumw with the parasite on Casamino Acids medium is greater tham that of $P$. glandicola. The increased spread of the curves of cultures on Casamino Acids is believed to be due to increased antolysis in the hout-parasite coltures and to contimued activity of the parasice.

As a comparison three other isolates of $P$. obluse from different hosts were inoculated with C. parasilimm on a potansimm nitrate nodium. Growth curves of cultures with and without the parasite are shown in Figure 30. Isolate 1130 was obtaninced from oak, I lafi from red bud (Cercis) and 1112 liom honey locust, all from West V'irginia. Growth curves of isolates 1130 and 11 (jo are very similar and both alre reduced sharply by the presence ol the parasite. The growele mrve of 1130 is more nearly like that of isolate 108.1 from apple (compare with Figure 28). Isolate 11 t2 differed from the others. It grew lapidls for

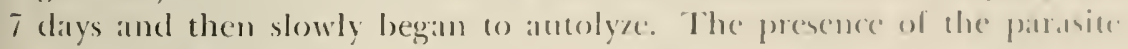

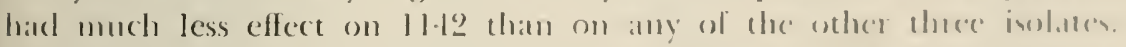

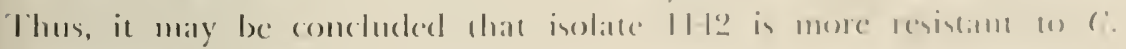
parasitirmm moler these comditions.

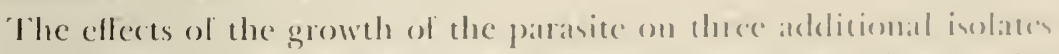

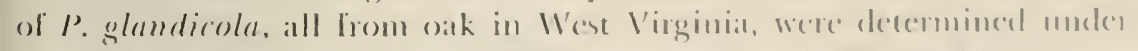
the same conditions. The growth arves anc shown in figme 31 .

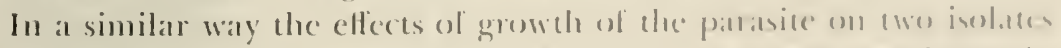

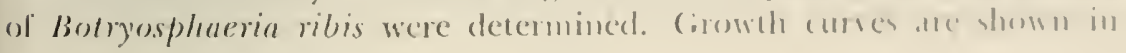




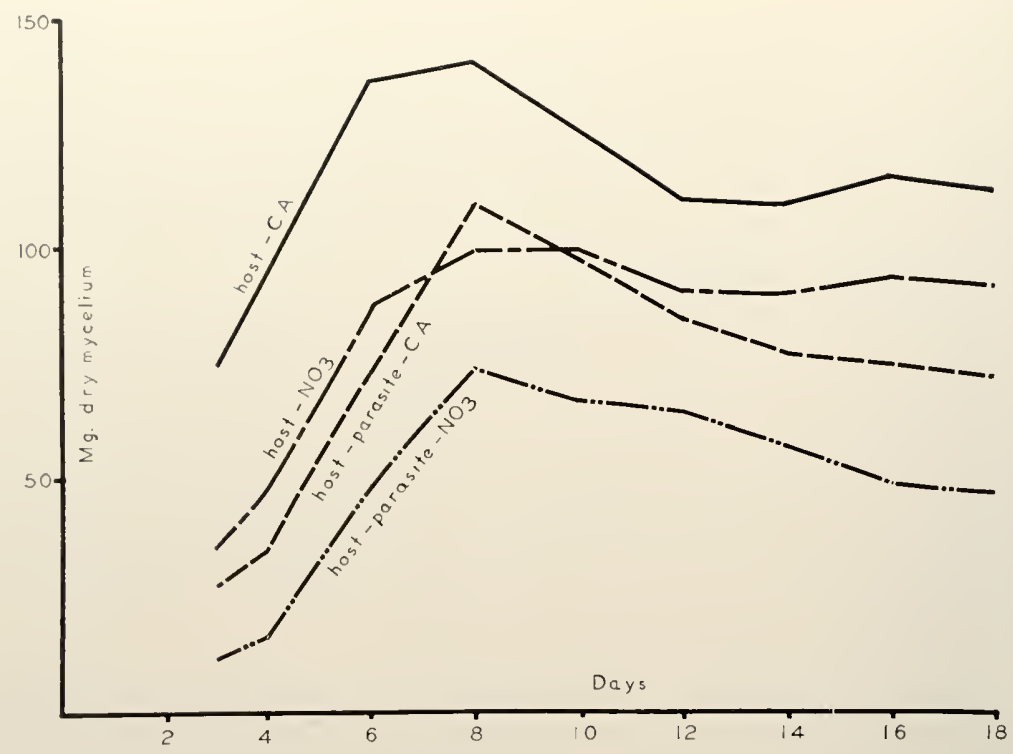

Figure 26. Growth of P. glandicola (isolate 1138) alone and with C. parasiticum in glucose-Casamino Acids and glucose-potassimm nitrate media.

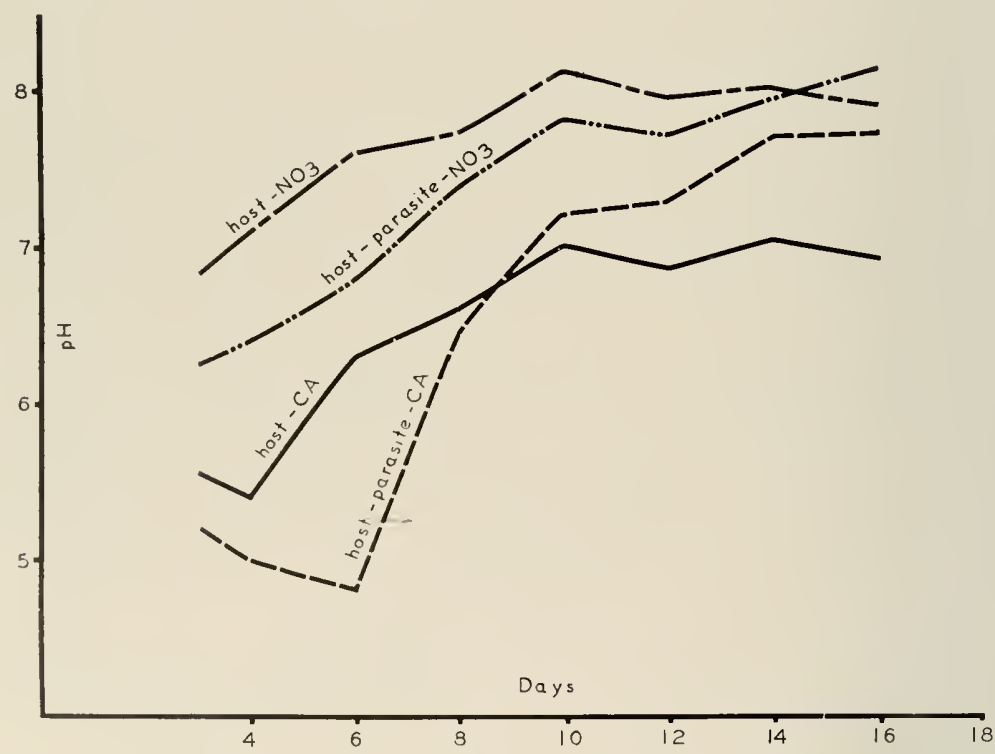

Figure 27. The $\mathrm{pH}$ of the filtrates of the same cultures reported in Figure 26. 


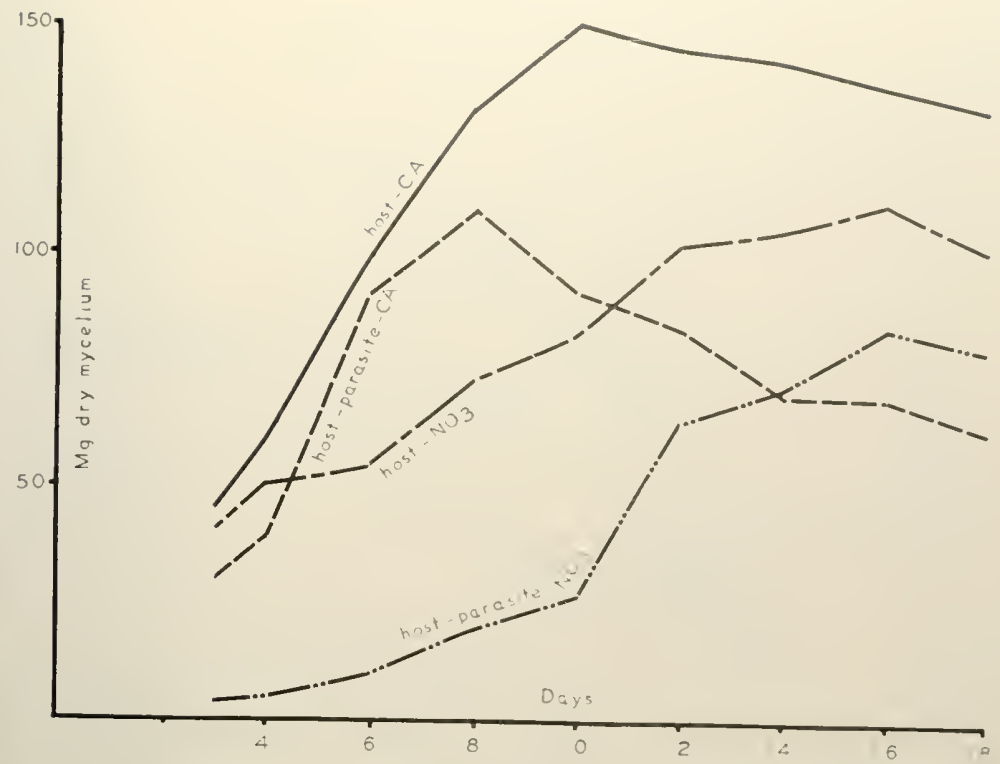

Figure 28. Growth of P. oblusa (isolate J(Rst) alone and with C. parasilirum in glucose-Casamino Acids and glucose-potassium nituate media.

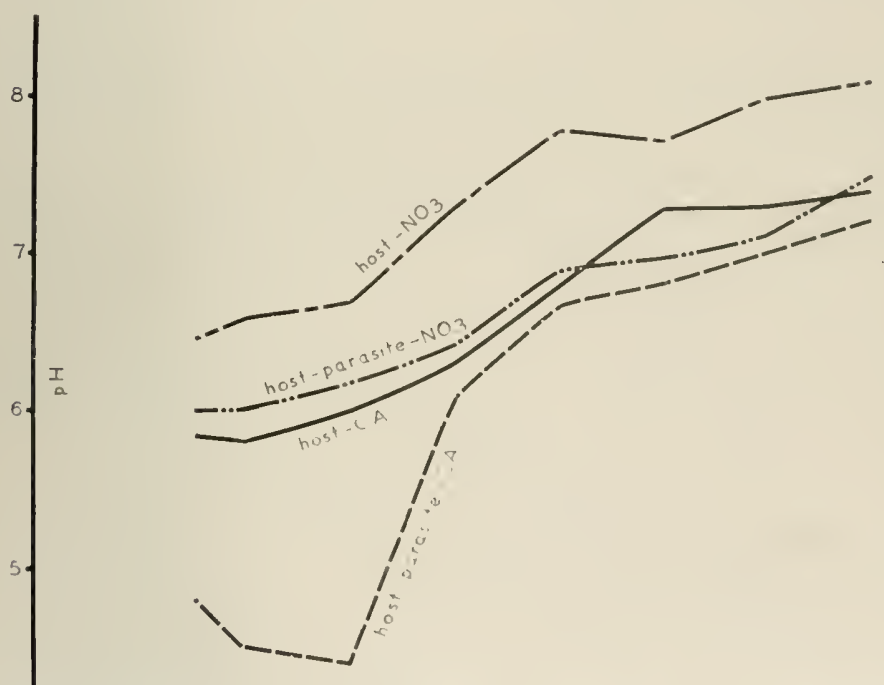

Days

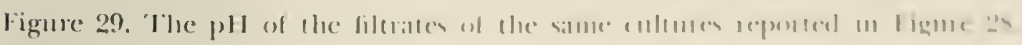




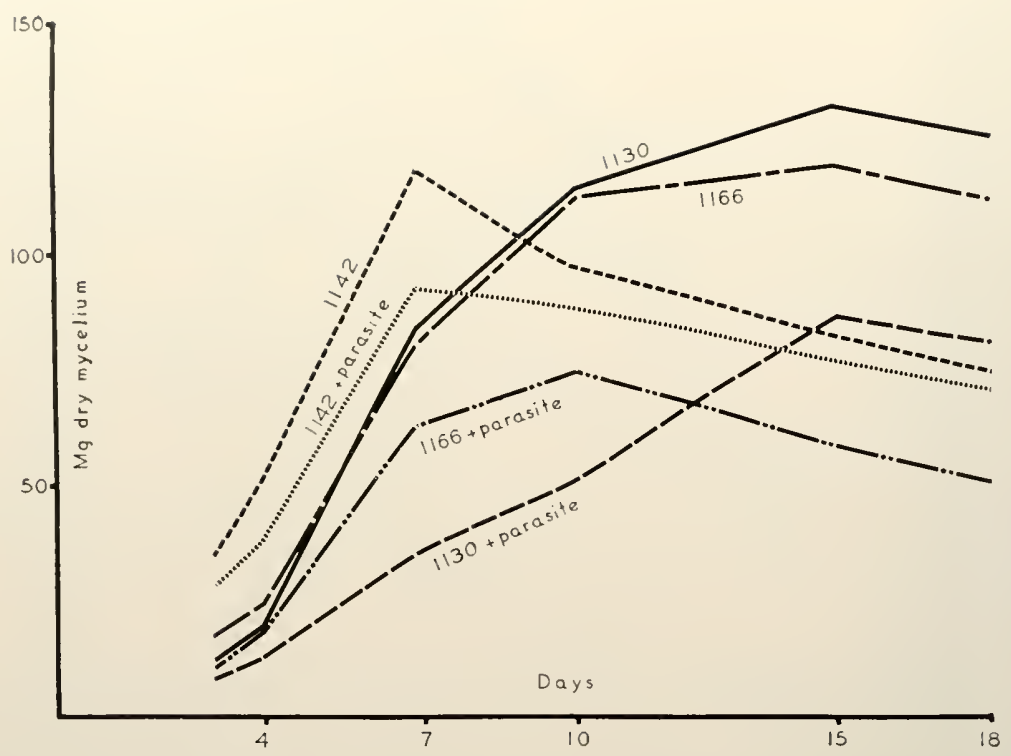

Figure 30. Comparison of growth of three additional isolates of $P$. obtusa alone and with C. parasiticum in a glucose-potassium nitrate medium.

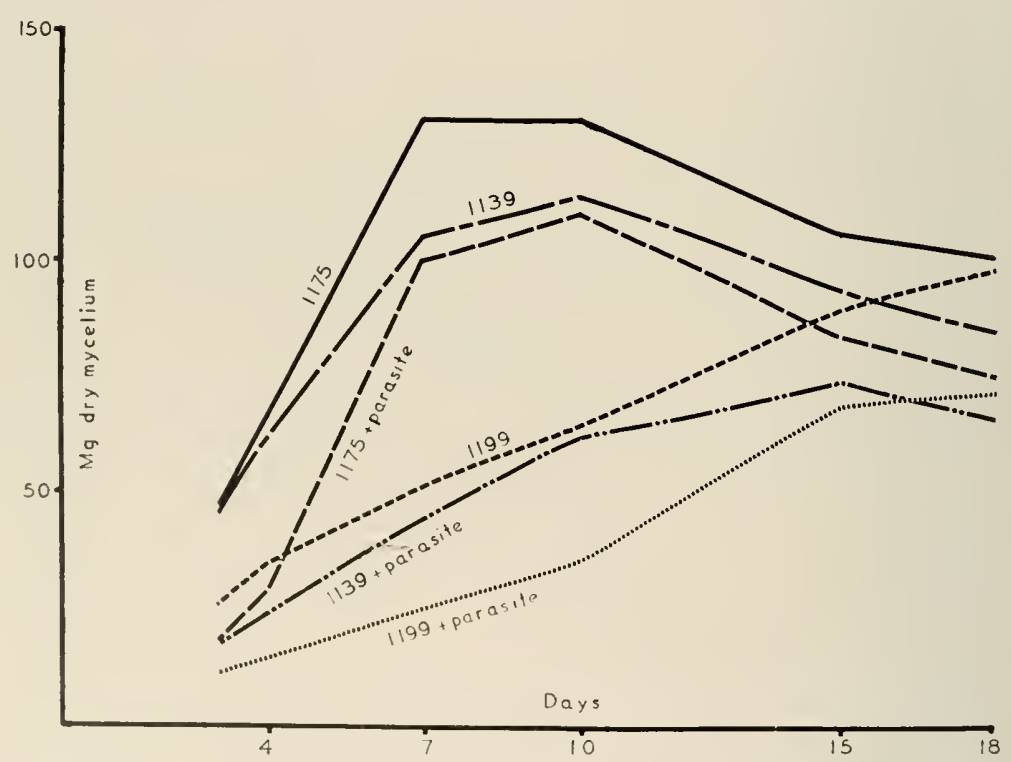

Figure 31. Comparison of growth of three additional isolates of $P$. glandicola alone and in combination with C. parasiticum in a glucose-potassium nitrate medium. 


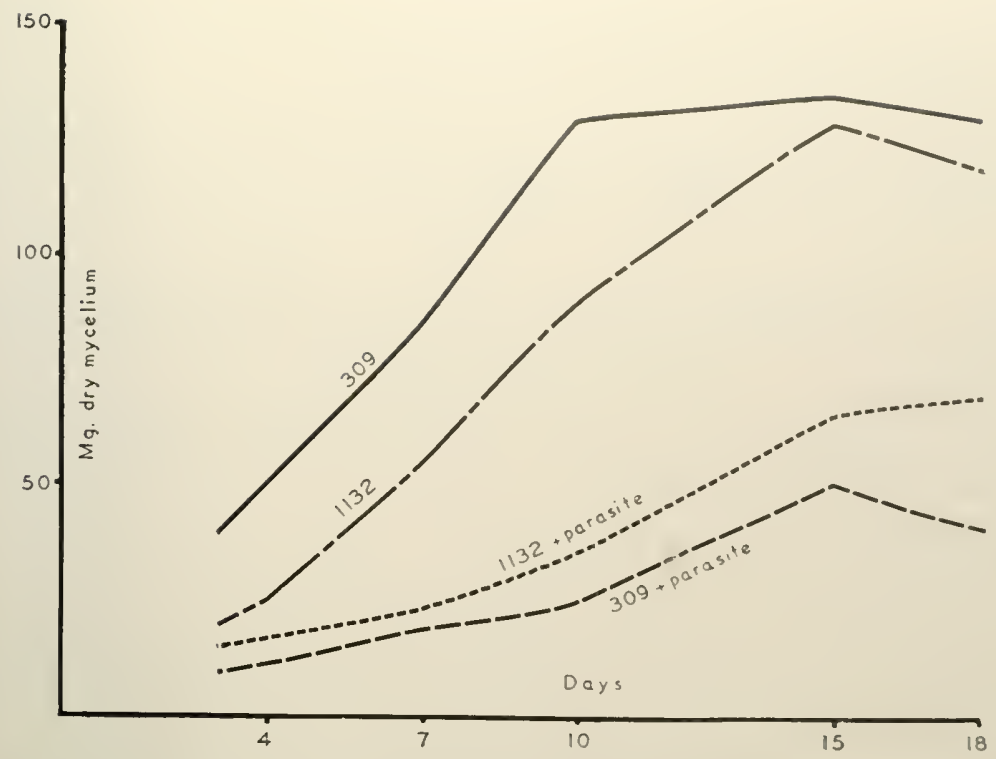

Figure 32. Comparison of growth of two isolates of Botryosphaeria ribis alone and in combination with $C$. parasiticum in a glucose-porassium nitrate medium.

Figure 32. Isolate No. 1132 was obtained from oak and No. 309 from apple. The response of these two isolates was sinilar and much like that of other species of host.

A few general conclusions may be drawn as a result of studying in some detail the responses of a total of 10 isolates from three highly susceptible species of host. Isolates from the same species ( $P^{2}$. glandicola) of host tree may vary considerably in their response (resistance) $10 \mathrm{C}$. parasiticum. There was sometines more difference between isolatus of the same species than between host species (compane l'. olluwsu and B. ribis). Growth of all host isolates tested was depresecel by dhe prenence of the parasite under these conditions. The degree of severity of pinat sitism was affected by the host medium ats well as the host speries. There was little difference in the virulence of isolates of C. parasilucum.

It has been noted above that the growth rate of the host. palticulanls P. obtusa, is less on a medium containing nitrate nitrogen than on one cons. laining Casamino Acids, yet the host mycelimm growing on lench meeliol was parasitized equally. It had been conchuded tentalliveis that latpid

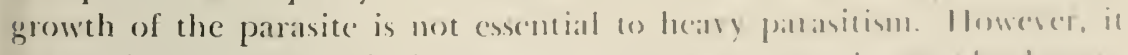

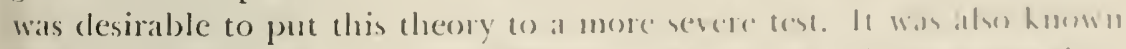

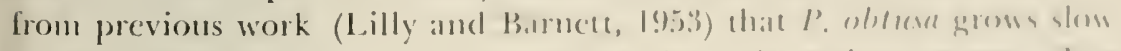

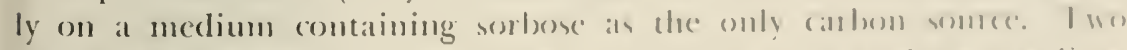

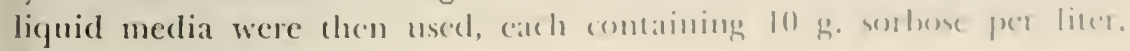


and 2 g. of Casamino Acids or 2 g. of potassimm nitrate per liter. Inoculation was by mycelinm of host and spores of the parasite. The parasite sporulated heavily on the losst mycelium on both media as soon as it reached the surface. Small submerged colonies of the host also were heavily parasitized and the parasite was sporulating. Dry weights of these cultures are presented in Table 4.

Table 4. Comparison of Growth of $P$. obtusa Alone and with the Parasite on Two Media Containing Sorbose. Dry IVeights Are Given in MG. PER Culture

\begin{tabular}{|c|c|c|c|}
\hline MEDIUM & DAYS & HOST ALONE & Host and Parasite \\
\hline Sorbose-nitrate & 21 & 53 & 10 \\
\hline Sorbose-nitrate & $\therefore 6$ & 86 & 14 \\
\hline Sorbose-Casamino Acids & 21 & 111 & 42 \\
\hline Sorbose-Casamino Acids & 36 & 91 & 72 \\
\hline
\end{tabular}

Even at the end of 36 days the host mycelimm alone had not reached maximum weight on the sorbose-nitrate medium, but maximum weight had been reached on the sorbose-Casamino Acids medium. The parasite caused severe inhibition of host growh on both media, being greater on the nitrate medimm, where little total weight was produced. Microscopic examination showed that nearly all of the mycelimm in the nitrate medium belonged to the parasite and only a little host mycelium was present. In the Casamino Acids medium the host was heavily parasitized but it still made greater growth than on the nitrate medium. This indicates that only a small amount of host mycelium is necessary for continued slow growth of the parasite.

\section{SUSCEPTIBILITY AND RESISTANCE TO THE PARASITE}

In the host range studies reported above it was found that all tested isolates of $P$. obtusa, $P$. glandicola and $B$. ribis were highly susceptible to $C$. parasiticum. Only minor variation in elegree of susceptibility was noted between isolates of the same species under uniform conditions and there was little difference between these three species of hosts. When 3-week-old cultures of these highly susceptible species were inoculated by placing drops of a spore suspension of the parasite on the older portions of the mycchim, the parasite began to grow within a lew days and slowly spread over the lost mycelium. In another test cultures of $P$. obtusa were grown lor 7 days (near maximum weight) in glucose-Casamino Acids liquid medium. The mycelium was washed thoroughly and placed in sterile distilled water for as $10 n g$ as 30 days. In all tests the aged, starved mycelium proved to be susceptible and was readily parasitized by $C$. parasiticum. 
'These experiments show that a compatible motritional aclationship can be cotablished by the paraste eren with ofd mocelinm and that the nutrients required by the parasite are present in the old and foumg mycelium alike. Neither growing celts nor at high elegrec of metaloslic activity is essential to parasitism. Maturity of cells of the mrcelium of these susceptible species is not a factor in resistance.

In considering possible ways by which the host fungi could be made. more resistant or more susceptible, the nitrogen source and concentrattion were among the most likely to be of importance. It was showin above that there was no great dillerence in the ellects of several nitrogen sources in approximately the same concentrations. Experiments were then designed to determine whether the concentration of amino acids or the carbon-nitrogen ratio in the host medium would alter the degree of parasitism by $C$. parasiticum. Liquicl media were made up containing glucose and Casamino Acids in the following amounts in g. per liter: 20-1, 10-2, 10-10, and 5-10. P. obtusa was used as the host fungur. The results of one experiment are shown in Figure 3.3.

The greatest amount of growth of the host alome (2) (2) mg) wals in the 20-1 medium, which allowed only little growth of the parasite as juelged visually. This is also reflected in the relatively slight depression in the total weight of host and parasite grown together. I reduction in

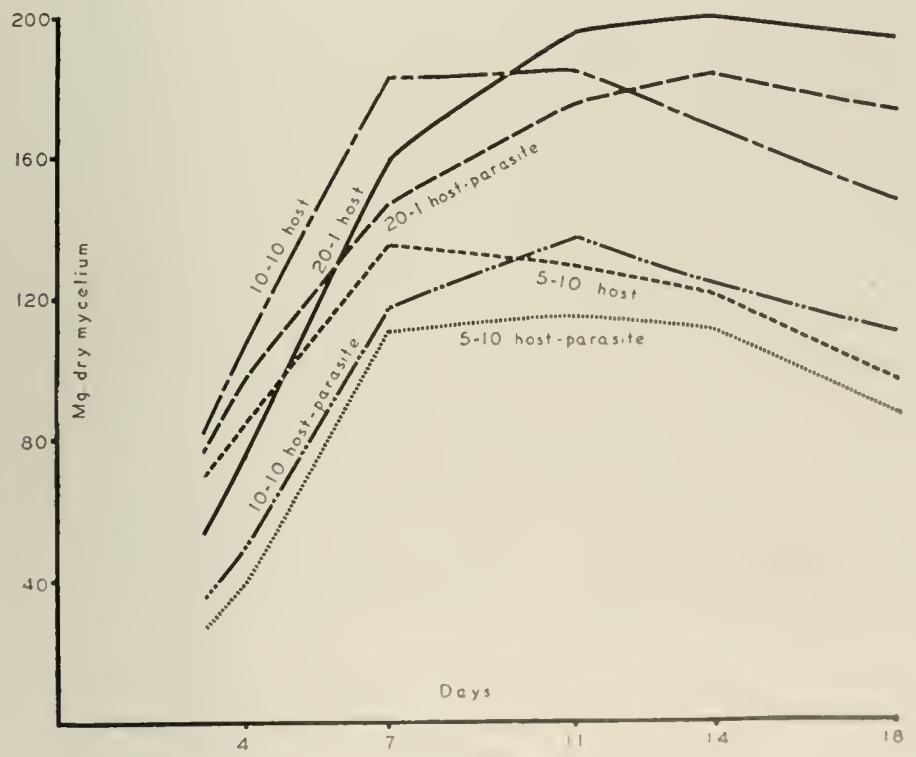

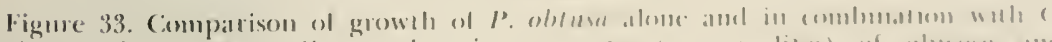

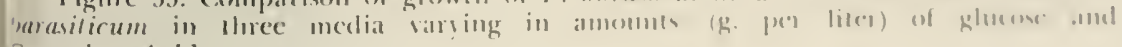
alsamino Acids. 
ghucose to $10 \mathrm{~g}$. and an increase in Ciasamino Acids to $2 \mathrm{~g}$. (not shown on graph) resulted in a decrease in maximum weight of host alone to $135 \mathrm{mg}$. The parasite made greater growth and caused a greater reduction in weight of the host-parasite cultures than on the 20 -1 medium. The 10-10 medium allowed greater maximum growth of the host alone (193 mg.) than did the $10-2$ medium, presumably because of the added carbon in the Casamino Acids. This medium permitted excellent growth of the parasite, a fact also reflected in the great decrease in weight of the host-parasite cultures as compared to the host alone. The two media containing $10 \mathrm{~g}$. of Casamino Acids per liter were surprisingly similar in the growth of the host and parasite together, regardless of the 2fold difference in the amount of ghucose present. Growth of the parasite on $P$. obtnsa was excellent in both media and most of the final weight in the 5-10 medimm is believed to be due to the parasite.

The effects of concentration of amino acids on resistance of $P$. ilicis and Coniothyrium. sp. to C. parasiticum were tested on agar media using lower concentrations of glucose and Casanino Acids. Agar media were used because these 2 host species were more resistant than $P$. obtusa and it was likely that they would show little or no depression of weight in liquid culture. These media contained the following proportions of glucose and Casamino Acids: 20-1, 10-1, 3-4, and 3-8. The agar plates were inoculated at three points with host mycelium and a spore suspension of the parasite was added to two of these areas. The amount of growth of C. parasiticum was estimated visually and classed in 4 groups ranging from 1 (slight; host highly resistant) to 4 (excellent; host highly susceptible). No visible growth of the parasite was recorded as negative. The results are summarized in Table 5. The results confirmed previous observations on other media that $P$. obtusa is highly

Table 5. Estimated Relative Growth of C. parasiticum on Three Hosts Cultered on Four Agar Media Differing in Concentrations of Glucose and Casamino Acins. Results Are Recorded in Five Groups: 0 (NONE), 1 (SLIGHT, HOST HIGHLY RESISTANT) TO 4 (EXCELLENT, HOST HIGHLY SUSCEPTIBLE)

\begin{tabular}{|c|c|c|c|c|}
\hline Host and TIME & $20 \Leftrightarrow \mathrm{LL}-1 \mathrm{CA}$ & 10 : $\mathrm{AL} .-1 \mathrm{CA}$ & $3 \Leftrightarrow \mathrm{L},-1 \mathrm{CA}$ & $\therefore(1 \mathrm{~L},-8 \mathrm{CA}$ \\
\hline 1'. olduste & - & & & \\
\hline 5 days & 2 & 2 & 2 & $\ddot{3}$ \\
\hline (1) days & 4 & 1 & 1 & 4 \\
\hline \multicolumn{5}{|l|}{ I'. incis is } \\
\hline 5 days & 11 & " & 1 & 1 \\
\hline 10 days & 1 & 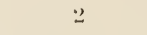 & 4 & 4 \\
\hline 14 days & 1 & 2 & 4 & + \\
\hline \multicolumn{5}{|l|}{ coniollyyrium sp. } \\
\hline$\tilde{i}$ days........... & "1 & 0 & 0 & 0 \\
\hline 10 days & 0 & 0 & 1 & 1 \\
\hline 14 days $\ldots \ldots \ldots \ldots . . . . . . . . .$. & 0 & 0 & 1 & 2 \\
\hline
\end{tabular}


susceptible. P. ilicis is intermediate in resistance, and Conim thy rmum sp. is highly resistant. While $P$. obtusa differed little in degree of usceptibility on these media, both $P$. ilicis and Coniothyrium sp. were decidedly more resistant on media containing a high carbon-nitrogen ratio. Both species showed the greatest susceptibility on media high in nitrogen and low in sugar. A comparison of resistance of two hosts in different media is shown in Figures $34-41$.

Thus, the results of these experiments confirm the theory that the degree of resistance of the hosts of $C$. parasiticum can be modified by changing the concentration of amino acids and the sugar in the medium. It is assumed that the mycelium grown on a higher concentration of amino acids contains within its cells a higher concentration of soluble nitrogenous compounds. It is possible that this is the basis for the degrec of susceptibility of the hosts. The validity of this theory must awatit further study of the nitrogen composition of the host mycelium, both quantitative and qualitative.

\section{GROWTH OF PARASITE IN THE ABSENCE OF A LIVING HOST}

It was reported above that little or no germination of spores of C. parasiticum occurred on water agar. Later it was discovered that the addition of a drop of water extract of the mycelium of $P$. obtusu (1) spores on water agar resulted in 75 per cent germination within 21 hours. Addition of the extract to spores on glucose-ycast extract agar alloc increased germination and resulted in the production of longer germ tubes that continued to grow slowly after some sporulation had occurred. More mycelium was produced than under any other condition in the absence of the living host. Repeated transfers from spores or mycelium and spores to fresh medium with added host extract resulted in no decrease in germination or in the growth of culures. In the absence of the host extract, development of the parasite did not go lixend the production of spores and a few hyphae on a yeast extract medimm in described above under spore germination.

Until the extract of host mycelimu was adeled to trimsters of 6 . parasiticum this species was thought (1) be all obligate parasile. How. crer, it was now clear that the parasite was able to athouls frome in medium all of the mutrients repuired for combinued tow growth and

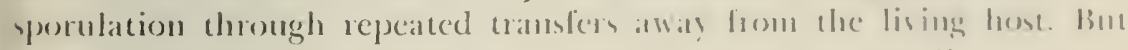
mone of the media tried, even with the acklition of the mocelimu cithate

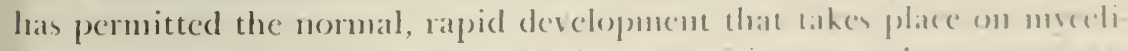
um of a living host. Pure cultures of C. parasiticum on glumese-seast in tract agar with added host extrace (ontinued on ypomblate on the sulface and within the agar, producing colonies in mben that appeared somsen fint

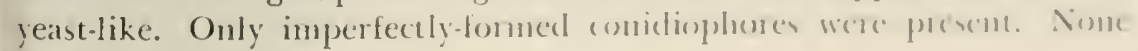
was truly verticillate. 

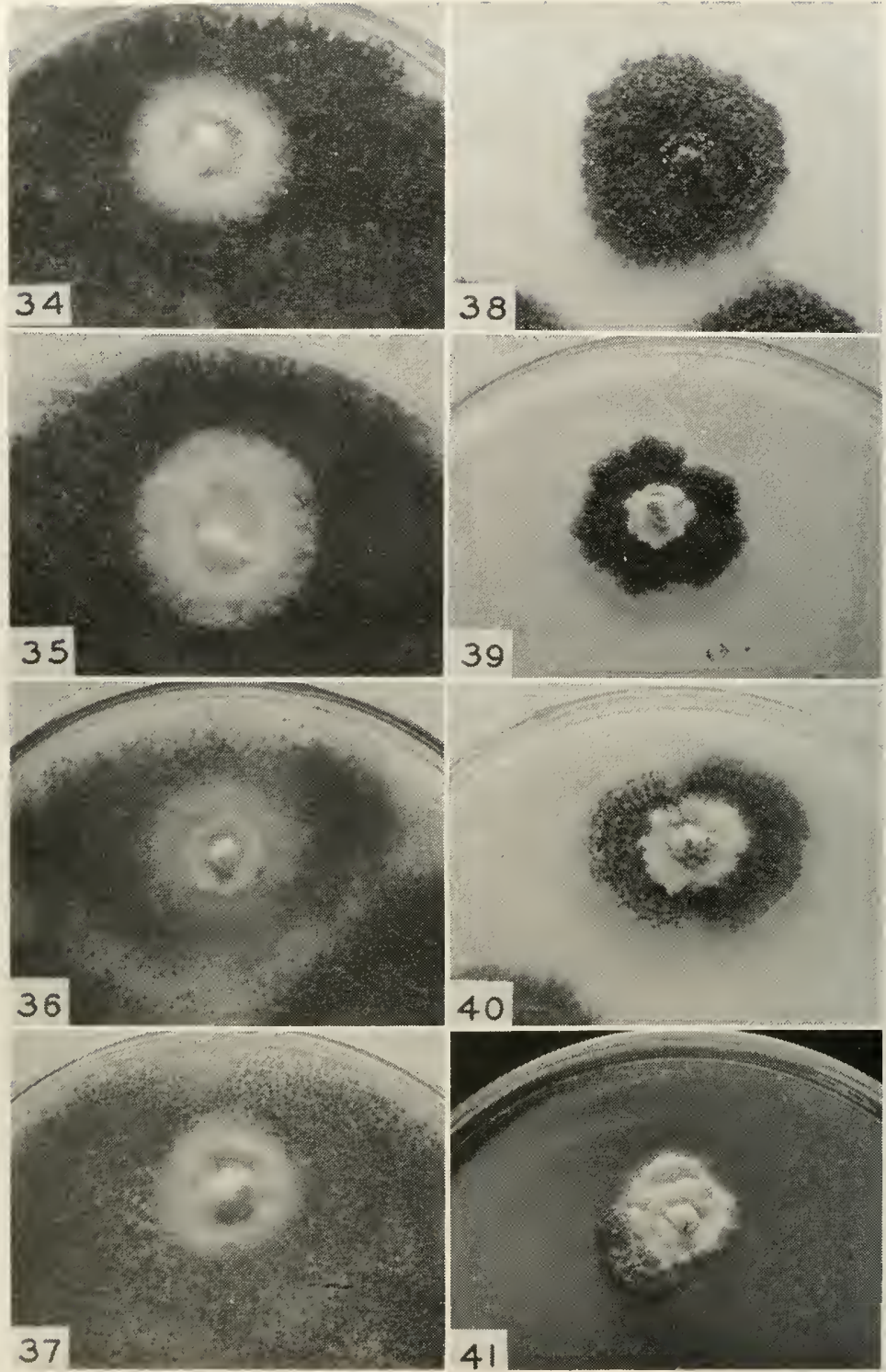

ligure 34-41. The effects of concentrations of glucose and Casamino Acids in the host medium on the growth of $C$. parasiticum on $P$. oblusa (34-37), a highly susceptible host, and $P$. ilicis $(38-41)$, a resistant host. Reading liom top to bottom the amounts per liter of glucose and Casamino Icils are 20-1, 10-2, 5-4, and 5-8. Note that there is little dilference in susceptibility of $P$. obtusa, but $P$. ilicis is much more resistant on the high carbon-low nitrogen medium. Cultures were 12 days old. 

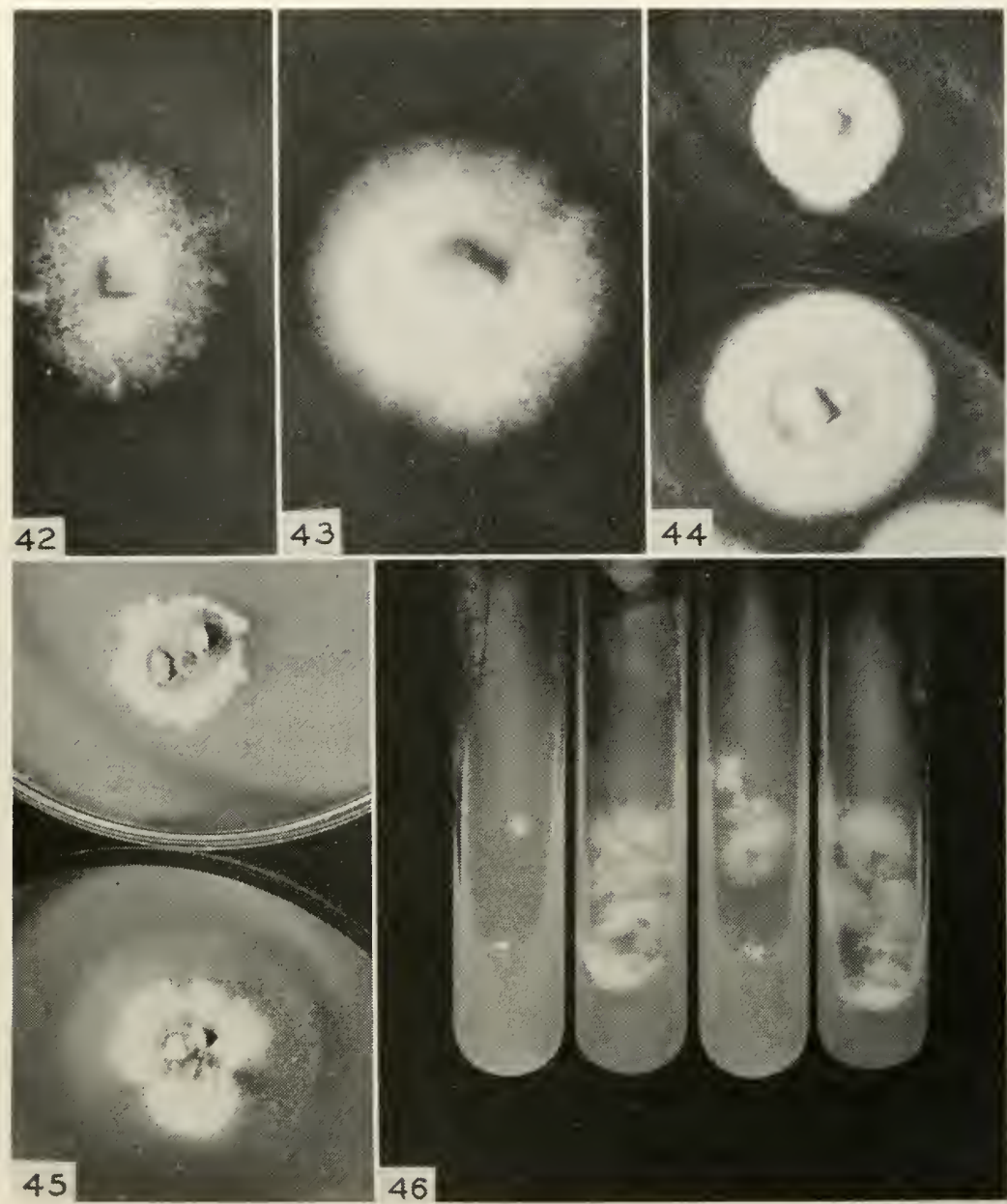

Figures 42-46. Comparison of $C$. parasiticum parent and mutant cultures, and growth of the parasite in the absence of a host. (42) Colony of parent culture of $C$. parasiticum on a glucose-yeast medimm fortified with one drop of concentrated extract of mycelium of $P$. obtusa, 16 days old. (43) Colony of mutant culture of C. paraviticum mnder the same conditions as the parent culture shown in 42 . (44) Comparative growtl of the parent culture (bottom) and the mutant (top) of C. forasilicum growing on a culture of $P$. obtusa. 12 davs old. (45) Comparative growtl of mutant cultme of $C$, parasiticum on glucose-yeasi extract agar at concentrations of 3-4, (bottom) and 20-1 (top), both supplemented with one drop of concentrated mincelial extract of $P$. obtusu. ( 46$)$ Eflect of 2 drops of extracts of three species of Physalospora on growth of the mutant of $C$. parasiticum on a glucose-yeast extract medium in the absence of a host. 1. No extract; B. Extract of P. obtusa; C. Extract of I'. ilicis; 1). Extract of $P$, thodina. Note that the extract of the immune species is nearly as effective in promoting growth as that of the highly susceptible species. cultures were 16 davs old. 
Under no condition tested comid the development of C. parasiticum in the absence of a living host be considered as normal for the suecies. as it is known on host mycclium. No typical verticillate conidiophores were present. Usually the sporogenoms cells arose simgly, dirculy from the mycelium. Spores were produced on the surface and within the agat medium. The most striking result of this experinent was the fact that the extract of $P$. rhodina supported growtl of the parasite nearly c(pual to that of $P$. obtusa. This simply means that the water suluble internal products of the two species are similar in respect to the materials that favor growth of $C$. parasilicum. The immunity of P'. Fodina ander the conditions tested is not due to the chemical comstitums that are casils extracted from the mycelimm.

\section{Discussion}

The discovery of an undescribed fungus parasitic on other common species of fungi is in itself of sufficient interest to justily at study of the mode of parasitism, host range, and factors allecting growth of the parasite. Calcarisporium parasiticum was found to be an excellent test organism for the study of the basic principles of the balanced type of parasitism. It was possible to investigate the stages in the host-paratsite relationship, including spore germination, tropism of host hyphae. host range, mode of parasitism, effect on the host, resistance, and growth of the parasite in the absence of the host.

The failure of the parasite spores to germinate in distilled water or on agar medium containing no added natural products is a datracter common to many parasitic fungi. The necessary spore germination lactor may be furnished by a number of natural products and appeass to be a common metabolic product of many fungi. It is mot destrosed by autoclaving. In these respects C. parasiticum seme to lx similar (o) Piptocephalis ariginiana (Berry and Bannett, 195i). lun it is cloubtful whether the germination factors required by spores ol these mo genceis are the same.

Growth of germ tubes of a parasite toward host tisste is shown ln many hosteparasite relationships imvolving higher planes (Varwexd. 1956i). Similar tropism of germ tubes of P'iptorephalis girgminmu towad host hyphate have been described (Berry and Barnete, lasi). Thare is little evidence that the germ tubes ol ci. parnsiticum are altranted to the host hyphae, except within a distance of a few microms of the hout. How.

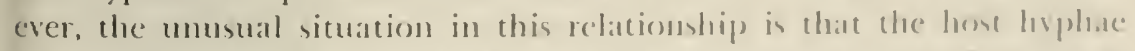
are lrequently strongly attracted towatel gentulateing spores of the partal

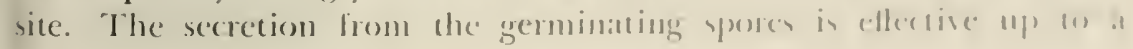


distance of about 10 microns, as shown by a change in the growth direction of the host hyphace It is aho of interest that hyphac of $P$. rhodima, which was immune to the parasite in all tests, are attracted to the parasite spores as strongly ats are the susceptible hosts.

The mode of parasitism of $C$. parasiticum is believed to be mmsual among the fungi, although the details of the process are not understood. No hamstoriat are produced, as in Piptocephalis (Berry and Banett, 1957; Dobbs and English, 1954), nor is there evidence of toxic secretions that kill the host cells, as shown by Rhizoctomio solani (Butler, 1957), Trichoderma (Weindling, 1932), or Papulospora (Warren, 1948). Contact of the host by the parasite is more nearly like that shown by Chaetocladium and Parasitella simplex (Burgeff, 1924), but these parasites are said to dissolve the host cell wall at the point of contact. There is no evidence of any dissolving action by $C$. parasiticum. In this respect this mode of parasitism is much like that shown by Taphrina, the smuts and certain others, which produce no haustoria and cause no destruction of host cells in the carly stages of parasitism. Yet, these parasites quickly establish a compatible nutritional relationship with living host cells.

At the point of contact between $C$. parasiticum and its host the walls are usually flattened and there seems to be some cohesive force holding them together. By use of the oil immersion objective of the microscope it was possible to see a very small cell that is formed at the tip of the parasite hypha where it contacts the host. It has not been determined whether this cell is always present at the points of contact. The buffer cell has not been observed in contacts of $P$. rhodina and the parasite. However, its presence is so frequent that it may be concluded that it has a specific function in the successful act of parasitism. Its function is unknown, but the most attractive theory, based on present knowledge, is that this small cell is a manufacturing mit producing and secreting enzymes or other substances that act to increase the permability of the plasma membrane of the host at the point of contact, and it possibly then functions to absorb nutrients from the host. There is also some evidence that the presence of the parasite later hastens attolysis of the host. This suggests that secretions from the parasite may pass through the buffer cell and increase the rate of metabolic activity of the host. These ideas have little factual support and they will be clifficult to verify. However, it is certain that the act of parasitism involves much more than mere absorption of soluble materials as a sponge absorbs water.

During the greater part of this investigation C. parasiticum was believed to belong to the group known as obligate parasites. It was not intil an extract of the host mycelimm was tested that it was cliscovered 
destroyed in the process of extraction, but this seems doubtful. It seems more probable that the parasite is unable to absorb the neeled nutrients lrom P. rhodina.

It is concluded that a successful parasitic relationship of Carcarisporium parasiticum is dependent upon (1) intimate contact with a potential host fungus, (2) the presence of specific nutrients in the host mycelium, (3) increased permeability of the host cells, and (4) ability of the parasite to absorb the nutrients from the host. After the parasitic relationship has been established with the host another set of factors may determine the degree of susceptibility or resistance. The higher degree of susceptibility of Physolospora ilicis and Coniothyrium sp. on a medium containing greater amounts of yeast extract or Casamino Acids is probably due to a difference in materials within the mycelium, possibly the soluble nitrogenous compounds. The known steps leading to parasitic and saprophytic growth are summarized in Figure 47.

The discovery of a mutant that produces a greater amount of mycelium and fewer conidia than the parent culture has made it possible to grow and measure the fungus by diameter of colony and by dry weight of the parasite and to study more easily the physiology of the parasite. This change in the growth habit of the parasite is believed to represent a true mutation, since it appeared several months after the isolate was discovered and after it had been transferred many times. The mutation was accompanied by little loss in its ability to parasitize susceptible hosts.

It is interesting that the known host range of $C$. parasiticum is limited to 3 species of Physalospora, Botryosphaeria ribis (taxonomically closely related to Physalospora), and some species of Dothiorella, Diplodia and Coniothyrimm that may have Physalospora as their perfect stages. It may be concluded that these fungi have physiological similarities. If the host range studies can be extended to authentic cultures of all known species of Physalospora and to many species of closely related genera, as well as many other pycnidium-forming fungi, it may be possible to use susceptibility under standard conditions as a taxomomic character to verify identification or tentatively identify species within this group of lungi. This would be particularly valuable in gromping non-sporulating cultures isolated lrou die-backs of trees and shrubs.

The present study has mucovered many more problems of parasitism than have been solved. It is proposed that the more important of these problens be investigated separately and more intensively. The problem of identifying the spore germination factor, the substance causing the uopism of host hyphae toward the parasite, and the growth stimulator in the liost extract is one which may require much time and the com bined cfforts of the mycologists and biochemists using modern methods 
normal mycelium; tall verticillate conidiophores

rapid parasitic growth

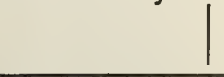

host-parasite contact favorable nutritional relationship

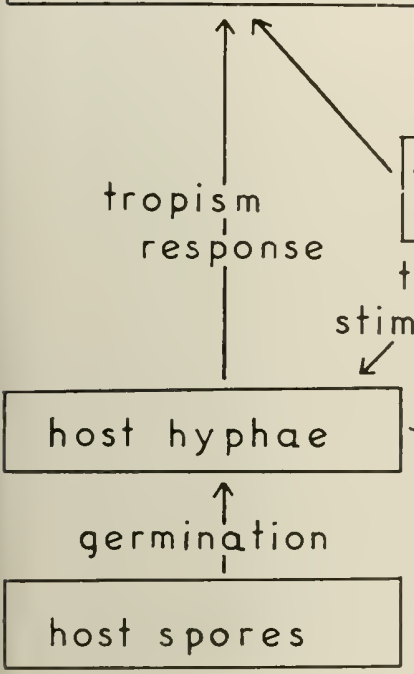

semi-synthetic medium

germ tubes and secondary spores trópism timulus

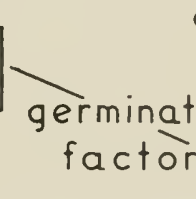

abnormal mycelium: mostly simple short conidiophores

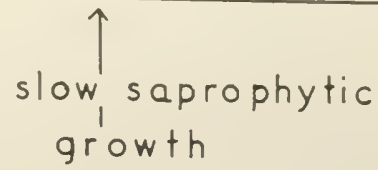

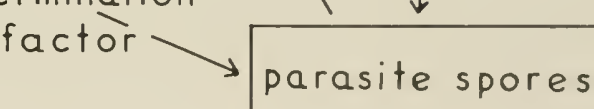

side of paigc).

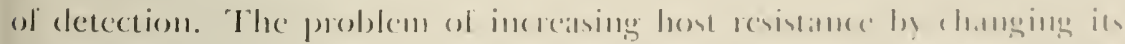

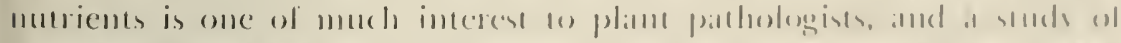

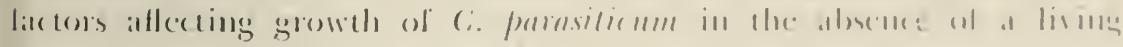

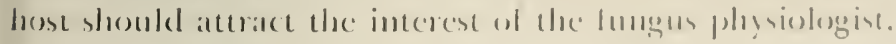

\section{Summary}

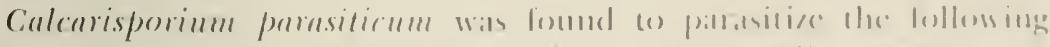

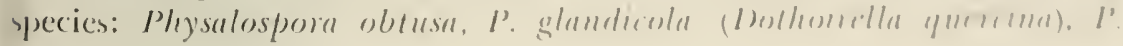


ilicis, Bolryosphaeria ribis, Guignardia bidwellii, diplodia pinea, Dothiorella sp. and Coniothyrium sp. Six species of Physalospora and more than 10 other fungi tested were not parasitized. Dilferences between isolates of the same species were apparent. Four isolates of the parasite were nearly equal in virulence.

The degree of susceptibility of $P$. ilicis and Coniothyrium sp. was increased by growth on a medimm high in concentration of amino acicls. A medium with high sugar concentration increased resistance. $P$. rhodinn remained immune under all conditions tested.

The spores of $C$. parasiticum failed to germinate in clistilled water or on water agar. The addition of natural products from various sources or trom a living host mycelium resulted in a high percentage of gemination. Germination is usually followed quickly by the production of secondary spores but further development of the parasite occurred only in the presence of a living host or upon the adclition of an extract of the mycelium of certain fungi. The mycelial extract permitted slow continned abnomal development, but nomal development occurred only on a living host. Extract of $P$. rhodina was nearly as effective in promoting growth of the parasite as was that of $P$. obtusn. The active principle in the extract is stable during autoclaving.

The germinating spores of $C$. parasiticmm secrete a substance that results in a positive tropism of the host hpyhac. Fim contact is cotal)lished between host and parasite but there is no penetration of the host cells. At the tip of the parasite hypha that contacts the host there is formed a small cell that is believed to function in some way to establish a compatible nutritional relationship with the host. Development of the parasite on the host is rapid and sporulation is abundant. A brief description of the morphology of the parasite, with illustrations, is given.

The only visible hamful effect of the parasite on the host is in the reduction in growth rate and possibly an increase in the rate of autolysis. The dry weights of the host-parasite cultures were less than that of the host alone under the same conditions. The carbon source, nitrogen source and $\mathrm{pH}$ of the host medium had little or no effect on the parasitc growing on Plysalospora obtusa.

The ustal appearance of $C$. parasiticum on glucose-yeast extract agan suplenented with host extract is somewhat yeast-like. Spores are produced on the surface and within the agar, but relatively little mycelium is produced. In one of these cultures there developed a mycelial mutant characterized by much more mycelium and fewer spores than the parent. This mutant was parasitic and only slightly less virulent than the parent culture. A relatively high concentration of amino acid in an agar medium supplemented with host extract favored the growth of both the mutant and its parent culture in the absence of a living host. 
